\title{
Long-term aspirin use for primary cancer prevention: An updated systematic review and subgroup meta-analysis of 29 randomized clinical trials
}

\author{
Qibiao $\mathrm{Wu}^{1,2}{ }^{\varpi}$, Xiaojun $\mathrm{Yao}^{1,2 \#}$, Hongwei Chen ${ }^{1,3 \#}$, Zhengtang Liu ${ }^{4 \#}$, Ting Li $\mathrm{Li}^{1,2}$, Xingxing Fan ${ }^{1,2}$, Guilin \\ Zhang ${ }^{1,2}$, Lili Yu $\mathbf{u}^{1,2}$, Min Chen ${ }^{1,2}$, Cong Xu1 ${ }^{1,2}$, Ruonan Zhang1,2,5,6, Bi Chen ${ }^{1,2,5,6}$, Xinbing Sui ${ }^{5,6}$ and Elaine \\ Lai-Han Leung $1,2 \bowtie$ \\ 1. State Key Laboratory of Quality Research in Chinese Medicine, Macau University of Science and Technology, Macau, China. \\ 2. Faculty of Chinese Medicine; Macau University of Science and Technology, Macau, China. \\ 3. Faculty of Medicine; Macau University of Science and Technology, Macau, China. \\ 4. Department of Geriatrics, Xiyuan Hospital of China Academy of Chinese Medical Sciences, Beijing, P.R. China. \\ 5. Holistic Integrative Pharmacy Institutes and Department of Medical Oncology, The Affiliated Hospital of Hangzhou Normal University, College of \\ Medicine, Hangzhou Normal University, Hangzhou, Zhejiang, China. \\ 6. Key Laboratory of Elemene Class Anti-cancer Chinese Medicine of Zhejiang Province and Engineering Laboratory of Development and Application of \\ Chinese Medicine from Zhejiang Province, Hangzhou Normal University, Hangzhou, Zhejiang, China. \\ \#Equal contributors and co-first authors. \\ $\bowtie$ Corresponding authors: E-mails: hzzju@zju.edu.cn (X. Sui), lhleung@must.edu.mo (E. Leung), qbwu@must.edu.mo (Q. Wu).
}

(c) The author(s). This is an open access article distributed under the terms of the Creative Commons Attribution License (https://creativecommons.org/licenses/by/4.0/). See http://ivyspring.com/terms for full terms and conditions.

Received: 2020.06.02; Accepted: 2020.08.24; Published: 2020.09.14

\begin{abstract}
Background and objective: Long-term aspirin use for the primary prevention of cancer remains controversial, and variations in the effect of aspirin use on cancer outcomes by aspirin dose, follow-up duration, or study population have never been systematically evaluated. The objective of this study was to evaluate the effect of aspirin on primary cancer prevention and to determine whether the effect differed according to aspirin dose, follow-up duration, or study population.

Materials and methods: Seven electronic databases were searched from inception to September 30, 2019. Randomized clinical trials (RCTs) that compared aspirin use versus no aspirin use in participants without pre-existing cancer and reported cancer outcomes were selected. Data were screened and extracted by different investigators. Analyses were performed using Review Manager 5.3 and Comprehensive Meta-Analysis 2.0. Total cancer incidence was defined as the primary clinical endpoint. Total cancer mortality, all-cause mortality, major bleeding, and total bleeding events were the secondary outcomes. Subgroup analyses were conducted based on aspirin dose, follow-up duration, and study populations.

Results: Twenty-nine RCTs that randomized 200,679 participants were included. Compared with no aspirin, aspirin use was not associated with significant reductions in total cancer incidence $(R R=1.01$, $95 \% \mathrm{Cl}: 0.97$ to $1.04, P=0.72)$, total cancer mortality $(\mathrm{RR}=1.00,95 \% \mathrm{Cl}: 0.93$ to $1.07, P=0.90)$, or all-cause mortality $(\mathrm{RR}=0.98,95 \% \mathrm{Cl}: 0.94$ to $1.02, P=0.31)$; however, aspirin use was associated with a $44 \%$ increase in the risk of major bleeding $(\mathrm{RR}=1.44,95 \% \mathrm{Cl}: 1.32$ to $1.57, P<0.00001)$ and a $52 \%$ increase in the risk of total bleeding events $(R R=1.52,95 \% \mathrm{Cl}: 1.33$ to $1.74, P<0.00001)$. Subgroup analyses demonstrated consistent results.

Conclusions: Long-term aspirin use in individuals without pre-existing cancer was not associated with a significant reduction in total cancer incidence, cancer mortality, or all-cause mortality; however, aspirin use was associated with a significant increase in the risk of bleeding. Therefore, aspirin is not an appropriate choice for the primary cancer prevention.
\end{abstract}

Key words: long-term; aspirin; cancer; primary prevention; systematic review; subgroup meta-analysis; randomized clinical trials 


\section{Introduction}

There were approximately 18.1 million new cancer cases and 9.6 million cancer deaths worldwide in 2018 and the cancer incidence and deaths have been rapidly increasing [1-5]. According to the WHO's report, $30-50 \%$ of cancer cases are preventable [6], but the methods for preventing cancer remain a major unanswered issue. There are some recognized prevention strategies, such as adopting healthy lifestyles, avoiding risk factors, etc. [6]. However, there are also some controversial interventions for primary cancer prevention, such as aspirin use.

Over the last few decades, continuous long-term aspirin intake has been used as a chemopreventive approach for primary cancer prevention [7-9]. Some studies have shown that this intervention reduced the morbidity and mortality rates of cancer [8-11]; however, some other studies have found no overall association between them [12, 13]. A few studies, including the ARRIVE and ASPREE trials, two high-quality randomized controlled trials (RCTs) published in 2018, demonstrated increased cancer incidence and mortality with aspirin use $[14,15]$. The results are conflicting, and the effect of aspirin on primary cancer prevention remains unclear and controversial.

A few previous meta-analyses have evaluated the role of aspirin use in primary cancer prevention, but most of them included observational trials or cohort studies which, compared with RCTs, might weaken the strength of the evidence [11, 12, 16-18]. Some studies only focused on one certain type of cancer $[16,19,20]$, one specific population, such as cardiovascular disease (CVD) prevention population $[12,21,22]$, or the effect of low-dose of aspirin [23].

Aspirin's effect on primary cancer prevention has not been clearly established, and subgroup analyses based on aspirin dose, follow-up period, and study population have not been comprehensively conducted $[12,18]$. The U.S. Preventive Services Task Force (USPSTF) emphasized the need for more research into the effect of long-term aspirin use on the overall occurrence of cancer according to various aspirin doses and by subgroups, including patient characteristics, baseline cancer risk, comorbid conditions, etc. $[12,18]$.

This updated meta-analysis included all eligible RCTs to further evaluate the efficacy and safety of aspirin use for primary cancer prevention and to determine whether the effect differs according to aspirin dose, follow-up duration, or study population.

\section{Methods}

We performed this systematic review and subgroup meta-analysis following the Preferred Reported Items for Systematic Review and Metaanalysis (PRISMA) guidelines [24]. This study has been registered with the International Prospective Register of Systematic Reviews (PROSPERO): CRD42019134083. The methods used in this systematic review were described in the published protocol [25]. Ethical approval was not required because all the materials were published studies.

\section{Data source}

Two independent reviewers (QB $\mathrm{Wu}$ and $\mathrm{HW}$ Chen) performed a comprehensive search of the PubMed, Embase, ClinicalTrials.gov, Anzctr.org.au, Cochrane Library, Google Scholar and ScienceDirect databases without restriction on language or publication period. A conventional search was also performed to find potential studies that were not indexed in the electronic databases. Furthermore, the reference lists of all the related articles were reviewed to identify potential RCTs. The last search date was September 30, 2019. No trials were excluded due to their publication status or language.

\section{Study selection}

All RCTs comparing aspirin versus no aspirin (defined as placebo or no treatment) and reporting cancer incidence and/or cancer deaths as outcomes were selected and assessed for inclusion in our research. The trials included in this study met the following criteria: (1) RCT study design; (2) participants without known preexisting cancer (primary prevention of cancer); (3) aspirin at any dose compared with no aspirin; (4) follow-up of at least 1 year; and (5) cancer incidence and/or cancer deaths reported as outcomes.

Exclusion criteria were as follows: (1) studies on secondary or tertiary prevention of cancer, treatment of cancer, cancer remission, cancer recurrence or cancer metastases; (2) studies in which the participants were nonhuman populations, pregnant women, institutionalized individuals or postsurgical patients; (3) studies of high-incidence familial cancer syndromes (e.g., Lynch syndrome, etc. ); (4) trials that were not RCTs; and (5) studies where the full-text article was unavailable or the data were unextractable.

All the candidate articles were screened by two independent investigators (QB Wu and HW Chen) on the basis of title and abstract. The full texts were retrieved for further evaluation according to the inclusion and exclusion criteria. All inclusion disagreements were resolved by consensus. 


\section{Data extraction}

Two investigators (QB Wu and $\mathrm{XJ}$ Yao) independently rated the included RCTs and extracted the data. An intention-to-treat (ITT) analysis was used to analyze the results whenever possible.

We summarized the characteristics of all included RCTs in Table 1 and performed a meta- analysis using Review Manager (RM) 5.3 (Copenhagen: The Nordic Cochrane Centre, The Cochrane Collaboration, 2014) and Comprehensive Meta-Analysis (CMA) 3.0 (Biostat, Englewood, NJ, United States; 2016) software to assess the effects of aspirin on cancer outcomes.

Table 1. Principal characteristics of the studies included in the meta-analysis

\begin{tabular}{|c|c|c|c|c|c|c|c|c|c|}
\hline Source & Trial design & $\begin{array}{l}\text { Jadad } \\
\text { score }\end{array}$ & Country & Study population & $\begin{array}{l}\text { Total } \\
\text { randomized }\end{array}$ & $\begin{array}{l}\text { Average } \\
\text { daily dose of } \\
\text { aspirin (mg) }\end{array}$ & Comparator & $\begin{array}{l}\text { Mean } \\
\text { follow-up }\end{array}$ & Outcomes \\
\hline AAA, 2010 [40] & RCT, double-blind & 5 & UK & $\begin{array}{l}\text { Aged } 50-75 \text { y with ankle brachial } \\
\text { index } \leq 0.95\end{array}$ & 3350 & 100 daily & Placebo & 8.2 & $1,2,3,4$ \\
\hline AFPPS, 2003 [41] & RCT, double-blind & 5 & US & $\begin{array}{l}\text { Individuals with a history of } \\
\text { colorectal adenoma }\end{array}$ & 1121 & $\begin{array}{l}81 \text { or } 325 \\
\text { daily }\end{array}$ & Placebo & 2.7 & $1,3,4$ \\
\hline AMIS, 1980 [42] & RCT, double-blind & 5 & US & $\begin{array}{l}\text { Aged } 30-69 \text { y with prior } \\
\text { myocardial infarction. }\end{array}$ & 4524 & 1000 daily & Placebo & 3 & 1,3 \\
\hline ARRIVE, 2018 [14] & RCT, double-blind & 5 & $\begin{array}{l}\text { Germany, Italy, } \\
\text { Ireland, Poland, } \\
\text { Spain, UK, US. }\end{array}$ & Males at increased risk of CVD & 12546 & 100 daily & Placebo & 6 & $1,2,3,4$ \\
\hline $\begin{array}{l}\text { ASCEND, } 2018 \\
{[43]}\end{array}$ & RCT, double-blind & 5 & UK & $\begin{array}{l}\text { Individuals with diabetes, aged } \\
\geq 40 \mathrm{y}\end{array}$ & 15480 & 100 daily & Placebo & 7.4 & $1,2,3,4$ \\
\hline ASPIRE, 2012 [44] & $\begin{array}{l}\text { Multi-center, RCT, } \\
\text { double-blind }\end{array}$ & 5 & $\begin{array}{l}\text { Australia, India, } \\
\text { New Zealand, } \\
\text { Singapore, } \\
\text { Argentina. }\end{array}$ & $\begin{array}{l}\text { Patients with unprovoked venous } \\
\text { thromboembolism }\end{array}$ & 822 & 100 daily & Placebo & 3.1 & $2,3,4$ \\
\hline ASPREE, 2018 [15] & RCT, double-blind & 5 & $\begin{array}{l}\text { Australia and } \\
\text { US. }\end{array}$ & The healthy elderly & 19114 & 100 daily & Placebo & 4.7 & $1,2,3,4$ \\
\hline BDS, 1988 [45] & $\begin{array}{l}\text { RCT, open-label, } \\
\text { Endpoint blind }\end{array}$ & 3 & UK & $\begin{array}{l}\text { Male physicians who were } \\
\text { apparently healthy. }\end{array}$ & 5139 & 500 daily & No aspirin & 6 & $2,3,4$ \\
\hline CDPA, 1980 [46] & RCT, double-blind & 5 & US & $\begin{array}{l}\text { Men with prior myocardial } \\
\text { infarction. }\end{array}$ & 1529 & 972 daily & Placebo & 1.8 & $2,3,4$ \\
\hline CLIPS, 2007 [47] & RCT, double-blind & 5 & Europe & $\begin{array}{l}\text { Patients with peripheral arterial } \\
\text { disease }\end{array}$ & 366 & 100 daily & Placebo & 2 & $2,3,4$ \\
\hline DAMAD, 1989 [48] & RCT, double-blind & 5 & France, UK & $\begin{array}{l}\text { Aged } 17-67 \text { years, type I or II DM; } \\
\text { early diabetic retinopathy }\end{array}$ & 475 & 990 daily & placebo & 3 & $1,2,3$ \\
\hline EAFT, 1993 [49] & RCT, double-blind & 5 & $\begin{array}{l}\text { Europe } \\
\text { (12 countries), } \\
\text { Israel. }\end{array}$ & $\begin{array}{l}\text { Aged }>25 \text { years, with prior TIA or } \\
\text { minor ischemic stroke }\end{array}$ & 782 & 300 daily & No aspirin & 2.3 & $2,3,4$ \\
\hline ESPS-2, 1996 [50] & $\begin{array}{l}\text { Multicenter, RCT, } \\
\text { double-blind }\end{array}$ & 5 & $\begin{array}{l}\text { Europe } \\
\text { (13 countries). }\end{array}$ & $\begin{array}{l}\text { Aged } \geq 18 \text { years; with prior TIA or } \\
\text { stroke }\end{array}$ & 6602 & 50 daily & No aspirin & 2 & $1,2,3,4$ \\
\hline ETDRS, 1992 [51] & $\begin{array}{l}\text { Multicenter, RCT } \\
\text { double-blind trial }\end{array}$ & 5 & US & $\begin{array}{l}\text { Aged 18-70 years; with DM and } \\
\text { diabetic retinopathy }\end{array}$ & 3711 & 650 daily & No aspirin & 5 & $2,3,4$ \\
\hline HOT, 1998 [52] & RCT, double-blind & 5 & $\begin{array}{l}26 \text { countries } \\
\text { across Europe, } \\
\text { North and South } \\
\text { America, Asia. }\end{array}$ & $\begin{array}{l}\text { Individuals with hypertension } \\
\text { aged } 50-80 \mathrm{y}\end{array}$ & 18790 & 75 daily & Placebo & 3.8 & $1,2,3,4$ \\
\hline $\begin{array}{l}\text { JPAD, } 2018[53] / \\
2017[54] / 2018[55]\end{array}$ & $\begin{array}{l}\text { RCT, open-label, } \\
\text { blinded end-point }\end{array}$ & 3 & Japan & $\begin{array}{l}\text { Individuals with diabetes aged } \\
30-85 \mathrm{y}\end{array}$ & 2539 & $\begin{array}{l}81 \text { or } 100 \\
\text { daily }\end{array}$ & No aspirin & $4.37 / 10.7$ & $1,2,3,4$ \\
\hline JPPP, 2018 [56] & $\begin{array}{l}\text { RCT, open label, } \\
\text { blind endpoint }\end{array}$ & 3 & Japan & $\begin{array}{l}\text { Individuals aged } 60-85 y \text {, with } \\
\text { hypertension, dyslipidemia, or } \\
\text { diabetes }\end{array}$ & 14658 & 100 daily & No aspirin & 6.5 & $1,2,3,4$ \\
\hline PARIS, 1980 [57] & RCT, double-blind & 5 & US, UK & Males and females with prior MI & 2026 & 972 daily & Placebo & 3.4 & $2,3,4$ \\
\hline $\begin{array}{l}\text { PHS, } 1989[58] / \\
1998[59]\end{array}$ & RCT, double-blind & 5 & US & $\begin{array}{l}\text { Disease-free male physicians aged } \\
40-84 \text { y }\end{array}$ & 22071 & $\begin{array}{l}162.5 \text { daily } \\
\text { (325 qod) }\end{array}$ & Placebo & $5 / 12$ & $1,2,3,4$ \\
\hline $\begin{array}{l}\text { POPADAD, } 2008 \\
{[60]}\end{array}$ & RCT, double-blind & 5 & UK & $\begin{array}{l}\text { Individuals with diabetes, ABPI } \\
\leq 0.99 \text {, aged } \geq 40 \mathrm{y}\end{array}$ & 1276 & 100 daily & Placebo & 6.7 & $1,2,3,4$ \\
\hline PPP, $2001[61]$ & $\begin{array}{l}\text { RCT, open-label, } \\
\text { blind endpoint }\end{array}$ & 3 & Italy & $\begin{array}{l}\text { Individuals with } \geq 1 \text { CVD risk } \\
\text { factor }\end{array}$ & 4495 & 100 daily & No aspirin & 3.6 & $1,2,3,4$ \\
\hline $\begin{array}{l}\text { REDUCE, } 2015 \\
\text { [62] }\end{array}$ & $\begin{array}{l}\text { Multicenter, RCT, } \\
\text { double-blind }\end{array}$ & 5 & $\begin{array}{l}\text { Europe, Canada, } \\
\text { US, Puerto Rico. }\end{array}$ & $\begin{array}{l}\text { Men at increased risk of prostate } \\
\text { cancer, aged } 48-77 \mathrm{y}\end{array}$ & 6390 & Unknown & Placebo & 4 & $1,3,4$ \\
\hline SALT, 1991 [63] & RCT, double-blind & 5 & Sweden & $\begin{array}{l}\text { Males and females with prior TIA } \\
\text { or stroke }\end{array}$ & 1360 & 75 daily & Placebo & 2.7 & $1,2,3,4$ \\
\hline SAPAT, 1992 [64] & RCT, double-blind & 5 & Sweden & $\begin{array}{l}\text { Aged } 30-80 \text { years with chronic } \\
\text { stable angina pectoris }\end{array}$ & 2035 & 75 daily & No aspirin & 4.2 & $1,3,4$ \\
\hline $\begin{array}{l}\text { seAFOod, } 2018 \\
\text { [65] }\end{array}$ & $\begin{array}{l}\text { Multicenter, RCT, } \\
\text { double-blind }\end{array}$ & 5 & UK & $\begin{array}{l}\text { Aged } 55-73 \text { years, at high risk in } \\
\text { the English Bowel Cancer } \\
\text { Screening Programme }\end{array}$ & 709 & 300 daily & Placebo & 5 & $1,2,3$ \\
\hline ТРТ, 1998 [66] & RCT, double-blind & 5 & UK & $\begin{array}{l}\text { Men aged } 45-69 y \text { at high risk of } \\
\text { CVD }\end{array}$ & 5499 & 75 daily & No aspirin & 6.8 & $2,3,4$ \\
\hline ukCAP, 2008 [67] & RCT, double-blind & 5 & UK, Denmark. & $\begin{array}{l}\text { Aged }<75 \text { years, had colorectal } \\
\text { adenoma removed }\end{array}$ & 945 & 300 daily & No aspirin & 3.4 & $1,2,3$ \\
\hline UK-TIA, 1991 [68] & RCT, double-blind & 5 & UK & Males and females with prior TIA & 2449 & 300 or 1200 & Placebo & 4 & $2,3,4$ \\
\hline
\end{tabular}




\begin{tabular}{|c|c|c|c|c|c|c|c|c|c|}
\hline Source & Trial design & $\begin{array}{l}\text { Jadad } \\
\text { score }\end{array}$ & Country & Study population & $\begin{array}{l}\text { Total } \\
\text { randomized }\end{array}$ & $\begin{array}{l}\text { Average } \\
\text { daily dose of } \\
\text { aspirin (mg) }\end{array}$ & Comparator & $\begin{array}{l}\text { Mean } \\
\text { follow-up }\end{array}$ & Outcomes \\
\hline WHS, 2005 [69] & RCT, double-blind & 5 & US & $\begin{array}{l}\text { or stroke } \\
\text { Female health professionals } \geq 45 y\end{array}$ & 39876 & $\begin{array}{l}\text { daily } \\
50 \text { daily } \\
\text { (100 qod) }\end{array}$ & Placebo & 10.1 & $1,2,3,4$ \\
\hline
\end{tabular}

Abbreviations: AAA, Aspirin for Asymptomatic AtherosclerosisTrial; AFPPS, The Aspirin/Folate Polyp Prevention Study; AMIS, Aspirin Myocardial Infarction Study; ARRIVE, Aspirin to Reduce Risk of Initial Vascular Events; ASCEND, A Study of Cardiovascular Events in Diabetes; ASPIRE, Aspirin to Prevent Recurrent Venous Thromboembolism trial; ASPREE, Aspirin in Reducing Events in the Elderly; BDS, British Doctors Study; CDPA, Coronary Drug Project Research; CLIPS, Critical Leg Ischaemia Prevention Study; CVD, cardiovascular diseases; DAMAD, the Dipyridamole Aspirin Microangiopathy of Diabetes study; DM, diabetes mellitus; EAFT, European atrial fibrillation trial; ESPS-2, European Stroke Prevention Study 2; ETDRS, Early Treatment Diabetic Retinopathy Study; HOT, Hypertension Optimal Treatment; JPAD, Japanese Primary Prevention of Atherosclerosis with Aspirin for Diabetes; JPPP, Japanese Primary Prevention Project; PARIS, The Persantine-Aspirin Reinfarction Study; PHS, Physicians'Health Study; POPADAD, Prevention of Arterial Disease and Diabetes; PPP, Primary Prevention Project; RCT, RCT controlled trial; T/C, treatment group/control group; REDUCE, the Reduction by Dutasteride of Prostate Cancer Events study; SAPAT, The Swedish Angina Pectoris Aspirin Trial; SALT, Swedish Aspirin Low-dose Trial; seAFOod, The Systematic Evaluation of Aspirin and Fish Oil Polyp Prevention Trial; TIA, transient ischemic attack, TPT, Thrombosis Prevention Trial; UK, the United Kingdom; US, the United States; ukCAP, The United Kingdom Colorectal Adenoma Prevention; UK-TIA, The United Kingdom transient ischaemic attack; WHS, Women's Health Study.

Some of the data for the AAA, HOT, BDS, and PHS trials were extracted from previous meta-analyses $[8,12,18]$

1.Total cancer incidence; 2 . Total cancer mortality; 3 . All-cause mortality; 4 . Bleeding outcome.

Two independent reviewers $(\mathrm{QB} \mathrm{Wu}$ and $\mathrm{HW}$ Chen) appraised the risk of bias in the included trials using the Cochrane Risk of Bias Tool for Randomized Controlled Trials. [26] The following criteria were used to evaluate bias in each trial: random sequence generation; concealment of allocation; blinding of participants and personnel; blinding of outcome assessment; incomplete data; selective reporting; and other bias. The risk of bias was classified as 'low', 'high', or 'unclear'. The Jadad scale was also used to evaluate the quality of the included trials and a trial was considered high quality if the Jadad score was 3 or greater [27].

If there were disagreements, a third reviewer (ELH Leung) independently repeated the extraction, analysis, and interpretation of the data, and disagreements were solved by discussion until a consensus was reached.

\section{Outcomes}

Total cancer incidence was defined as the primary clinical endpoint. Total cancer mortality, all-cause mortality, major bleeding, and total bleeding events were the secondary outcomes.

\section{Subgroup analysis}

We performed subgroup analyses of total cancer incidence, total cancer mortality, all-cause mortality, and bleeding events based on aspirin dose, follow-up duration, and study populations.

\section{Data synthesis}

All analyses were performed using RM 5.3, CMA 3.0 and Trial Sequential Analysis (TSA) software (Copenhagen Trial Unit, Centre for Clinical Intervention Research, Copenhagen, Denmark; 2011). Dichotomous data were summarized as risk ratios (RR) with 95\% confidence intervals (CIs). Heterogeneity among the studies was assessed using the I-squared test. Substantial heterogeneity was indicated by $I^{2}>50 \%$, and a random-effects model was used (Review Manager version 5, Cochrane Collaboration, Copenhagen, Denmark) to estimate the summary RR and 95\% CI; otherwise, a fixed-effects model was applied [26, 28-33]. If quantitative synthesis was not appropriate, a systematic narrative synthesis of the information was provided to summarize and explain the features and findings of the included RCTs [25, 34-36]. The Grading of Recommendations Assessment, Development and Evaluation (GRADE) working group methodology was used to assess the strength of the body of evidence [37].

Egger's test and funnel plots were applied to examine the potential bias in the RCTs included in the meta-analysis when the number of RCTs was $\geq 10$ [38].

Subgroup analysis, sensitivity analysis, and Trial Sequential Analysis were applied to assess the robustness of the results and calculate the required sample size in the meta-analysis. [39] We also performed a meta-regression analysis to examine the potential heterogeneity and the impact of the moderator variables on the study effect size.

\section{Quality of evidence}

The risk of bias for each included study was evaluated by two independent reviewers (QB Wu and $X J$ Yao) using the GRADE approach [37]. Disagreements regarding a quality downgrade or upgrade were discussed with the third reviewer $(\mathrm{XJ}$ Yao) until a consensus was reached. The quality of the evidence was classified into four levels: "high", "moderate", "low" and "very low". The quality of evidence was downgraded according to five domains: (I) limitation of the study design, (II) inconsistency, (III) indirectness, (IV) imprecision, (V) publication bias [37]. 


\section{Results}

\section{Study search and study characteristics}

As shown in Supplementary Figure S1, 1,369 records were identified through the literature search; 572 of them were duplicates. Reviews, letters, case reports, and basic research were removed after the titles and abstracts were read $(n=671)$. The full texts of 126 candidate papers were then evaluated, and 97 were removed for the following reasons: duplicated data reported $(\mathrm{n}=38)$, nonrandomized controlled study design $(\mathrm{n}=35)$, insufficient data $(\mathrm{n}=$ 18), and familial cancer syndromes $(\mathrm{n}=6)$. In total, 29 trials met the inclusion criteria [14, 15, 40-69].

These 29 RCTs, which comprised 200,679 individuals, were included (Supplementary Figure S1 and Table 1) [14, 15, 40-69]. The included RCTs were performed and published from 1976 to 2018. The number of participants in each RCT varied from 475 to 39,876 . The mean (or median) age of the participants ranged from 44 to 74 years in the different trials. All the included RCTs compared aspirin to placebo or no treatment. Sixteen trials used a daily aspirin dose $\leq 100 \mathrm{mg}$ for the participants, four trials used a dose of 100-300 mg/d (one trial used $325 \mathrm{mg}$ every other day, and $162.5 \mathrm{mg} / \mathrm{d}$ was regarded as the daily dose), six trials used $>300 \mathrm{mg} / \mathrm{d}$, one trial used $81 \mathrm{mg} / \mathrm{d}$ or $325 \mathrm{mg} / \mathrm{d}$ in different groups, one used $300 \mathrm{mg} / \mathrm{d}$ or $1200 \mathrm{mg} / \mathrm{d}$ in different groups, [68] and one did not clearly report the daily dose of aspirin [62]. The mean follow-up ranged from 1.8 to 12 years. The characteristics of the 29 trials are shown in Table 1.

\section{Risk of bias and methodologic quality}

The risk of bias and methodologic quality of all the included RCTs were evaluated and are presented in Table 1, Supplementary Table S1 and Supplementary Figure S2, S3. The methodologic quality of all the included RCTs was high; twenty-five trials scored 5 out of 5 for methodological quality (Jadad score), and four trials scored 3 out of 5 (Tables 1 ). The randomization methods were distinctly reported in all trials. Twenty-five trials were double-blinded. Four trials were open-label and end-point blinded; allocation concealment and blinding of the participants and personnel contributed to a high risk of bias in these four trials $[45,53,56,61]$. In all included trials, the data were complete. The presence of any other bias was not clear (Supplementary Table S1 and Supplementary Figure S2, S3).

\section{Outcome measures}

The findings of the meta-analyses are summarized in Table 2.

\section{Total cancer incidence, cancer mortality and all-cause mortality}

Twenty-one of the included RCTs involving 179,518 participants observed and reported total cancer incidence, the primary clinical endpoint of this study; the pooled data showed that compared with no aspirin, aspirin use was not associated with a significant reduction in total cancer incidence $(\mathrm{RR}=$ 1.01, $95 \%$ CI: 0.97 to $1.04, P=0.72$ ) (Table 2; Figure 1A).

The results of the meta-analyses also showed that the total cancer mortality rate $(\mathrm{RR}=1.00,95 \% \mathrm{CI}$ : 0.93 to $1.07, P=0.90$ ) and all-cause mortality rate (RR $=0.98,95 \%$ CI: 0.94 to $1.02, P=0.31$ ) were not significantly different between the aspirin and no-aspirin groups (Table 2; Figure 1B and $1 \mathrm{C}$ ).

No significant heterogeneity was found for any of the three outcomes $\left(I^{2}=27 \%, 26 \%\right.$ and $45 \%$, respectively), and the fixed-effects model was used to pool the trial results.

\section{Bleeding events}

The summary estimates indicated that compared with no aspirin, aspirin use significantly increased the risk of major bleeding by $44 \%(\mathrm{RR}=1.44,95 \% \mathrm{CI}: 1.32$ to $1.56, P<0.00001$ ) (Table 2; Figure 2A) and the risk if total bleeding events by $52 \%$ ( $R R=1.52,95 \% \mathrm{CI}: 1.33$ to $1.74, P<0.00001$ ) (Table 2; Figure 2B).

\section{Subgroup analyses}

Subgroup analyses of total cancer incidence, cancer mortality and all-cause mortality based on aspirin dose

The results of the subgroup analyses based on aspirin dose showed that different daily dose of aspirin were not associated with a significant reduction in total cancer incidence $[\leq 100 \mathrm{mg}(\mathrm{RR}=$ 1.02, 95\% CI: 0.98 to $1.06, P=0.31) ; 100-300 \mathrm{mg}$ (RR = 1.01, $95 \%$ CI: 0.82 to $1.24, P=0.92)$; $>300 \mathrm{mg}(\mathrm{RR}=$ 1.01, 95\% CI: 0.83 to $1.23, P=0.91$ )] (Table 2; Supplementary Figure S4A), total cancer mortality [ $\leq$ $100 \mathrm{mg}(\mathrm{RR}=1.01,95 \% \mathrm{CI}: 0.94$ to $1.08, P=0.85)$; $100-300 \mathrm{mg}(\mathrm{RR}=1.04,95 \% \mathrm{CI}: 0.80$ to $1.35, P=0.76)$; > $300 \mathrm{mg}$ (RR $=0.91,95 \% \mathrm{CI}: 0.68$ to $1.22, P=0.53)]$ (Table 2; Supplementary Figure S4B), or all-cause mortality [ $\leq 100 \mathrm{mg}$ (RR $=0.97,95 \% \mathrm{CI}: 0.93$ to $1.01, P$ $=0.16) ; 100-300 \mathrm{mg}(\mathrm{RR}=0.94,95 \% \mathrm{CI}: 0.83$ to $1.07, P=$ $0.36)$; $>300 \mathrm{mg}$ (RR $=0.94,95 \% \mathrm{CI}: 0.86$ to $1.01, P=$ 0.11)] (Table 2; Supplementary Figure S4C).

The meta-regression analysis showed that total cancer incidence, cancer mortality or all-cause mortality did not vary significantly with respect to daily dose of aspirin (from $\leq 100 \mathrm{mg}$ to $>300 \mathrm{mg}$ ) (Supplementary Figure S5). 
Table 2. Summary of findings: long-term aspirin use for cancer primary prevention

\begin{tabular}{|c|c|c|c|c|c|c|c|c|}
\hline \multirow[t]{2}{*}{ Outcomes } & \multirow{2}{*}{$\begin{array}{l}\text { No. of } \\
\text { Studies }\end{array}$} & \multicolumn{2}{|c|}{ Events/no. of patients } & \multirow[t]{2}{*}{$I^{2}$} & \multirow[t]{2}{*}{ Statistical method } & \multirow{2}{*}{$\begin{array}{l}\text { Relative risk } \\
(95 \% \mathrm{CI})\end{array}$} & \multirow[t]{2}{*}{$P$ value } & \multirow{2}{*}{$\begin{array}{l}\text { Quality of the } \\
\text { evidence (GRADE) }\end{array}$} \\
\hline & & Aspirin & No Aspirin & & & & & \\
\hline Total cancer incidence & 21 & $5622 / 89673$ & $6001 / 89845$ & 27 & RR (fixed), 95\% CI & 1.01 (0.97 to 1.04$)$ & 0.72 & $\oplus \oplus \oplus \oplus$ High \\
\hline Total cancer mortality & 25 & $1634 / 88020$ & $1577 / 84224$ & 26 & RR (fixed), 95\% CI & 1.00 (0.93 to 1.07$)$ & 0.90 & $\oplus \oplus \oplus \oplus$ High \\
\hline All-cause mortality & 28 & $5225 / 97303$ & $4927 / 93129$ & 45 & RR (fixed), 95\% CI & 0.98 (0.94 to 1.02$)$ & 0.31 & $\oplus \oplus \oplus \oplus$ High \\
\hline Major bleeding events & 18 & $1288 / 85851$ & $887 / 83933$ & 0 & RR (fixed), 95\% CI & 1.44 (1.32 to 1.57$)$ & $<0.00001^{*}$ & $\oplus \oplus \oplus \oplus$ High \\
\hline Total bleeding events & 19 & $4123 / 63519$ & $2896 / 60495$ & 56 & RR (random), 95\% CI & $1.52(1.33$ to 1.74$)$ & $<0.00001^{*}$ & $\oplus \oplus \oplus \mathrm{O}$ Moderate \\
\hline
\end{tabular}

Subgroup analyses

Total cancer incidence

Dose of aspirin

$\leq 100 \mathrm{mg} / \mathrm{d}$

$100-300 \mathrm{mg} / \mathrm{d}$

$>300 \mathrm{mg} / \mathrm{d}$

Follow-up duration

1-5 years

5-10 years

$>10$ years

Study population

Healthy population

With DM

With CVD or at increased risk of CVD

At increased risk of cancer

With peripheral arterial disease or venous 2

thromboembolism

Total cancer mortality

Dose of aspirin

$\leq 100 \mathrm{mg} / \mathrm{d}$

$100-300 \mathrm{mg} / \mathrm{d}$

$>300 \mathrm{mg} / \mathrm{d}$

Follow-up duration

$1-5$ years

5-10 years

$>10$ years

Study population

Healthy population

With DM

With CVD or at increased risk of CVD

At increased risk of cancer

12

3

2

With peripheral arterial disease or venous 3

thromboembolism

All-cause mortality

Dose of aspirin

$\leq 100 \mathrm{mg} / \mathrm{d}$

$100-300 \mathrm{mg} / \mathrm{d}$

$>300 \mathrm{mg} / \mathrm{d}$

Follow-up duration

$1-5$ years

5-10 years

$>10$ years

Study population

Healthy population

With DM

With CVD or at increased risk of CVD

At increased risk of cancer

With peripheral arterial disease or venous 2

thromboembolism

Dose of aspirin and follow-up duration

Aspirin $\leq 100 \mathrm{mg} / \mathrm{d}$

for more than five years

Total cancer incidence

Total cancer mortality

All-cause mortality

Major bleeding events

Dose of aspirin

$\leq 100 \mathrm{mg} / \mathrm{d}$

$100-300 \mathrm{mg} / \mathrm{d}$
8
$4920 / 80446 \quad 4835 / 80593 \quad 38 \quad$ RR (fixed), $95 \%$ CI $\quad 1.02$ (0.98 to 1.06$) \quad 0.31$ $185 / 11509 \quad 183 / 11501 \quad 0 \quad$ RR (fixed), $95 \%$ CI $\quad 1.01$ (0.82 to 1.24$) 0.92$ 256/6068 $154 / 4349 \quad 9 \quad$ RR (fixed), $95 \%$ CI $\quad 1.01$ (0.83 to 1.23$) \quad 0.91$

$1944 / 30394 \quad 2477 / 32249 \quad 3 \quad$ RR (random), $95 \%$ CI 0.99 (0.93 to 1.05 ) 0.65 $1918 / 27049 \quad 1706 / 25343 \quad 64 \quad$ RR (random), 95\% CI 1.01 (0.90 to 1.14 ) 0.82 $1760 / 32230 \quad 1764 / 32253 \quad 0 \quad$ RR (random), $95 \%$ CI 1.00 (0.94 to 1.06$) 0.96$

$2786 / 439252651 / 42275 \quad 0 \quad$ RR (random), 95\% CI 1.02 (0.97 to 1.07 ) 0.54 $1099 / 9637 \quad 1124 / 9655 \quad 33 \quad$ RR (random), $95 \%$ CI 0.95 (0.84 to 1.08 ) 0.42 $1246 / 319721182 / 31847 \quad 52 \quad$ RR (random), 95\% CI 1.04 (0.92 to 1.19$) \quad 0.50$ $326 / 2589 \quad 775 / 4008 \quad 48 \quad$ RR (random), $95 \%$ CI 1.00 (0.66 to 1.54 ) 0.99 $70 / 1049 \quad 86 / 1049 \quad 0 \quad$ RR (random), $95 \%$ CI 0.81 (0.60 to 1.10 ) 0.18

$1413 / 66181 \quad 1406 / 66316 \quad 29 \quad$ RR (fixed), $95 \%$ CI $\quad 1.01$ (0.94 to 1.08$) \quad 0.85$ $112 / 12895 \quad 107 / 12869 \quad 0 \quad$ RR (fixed), $95 \%$ CI $\quad 1.04$ (0.80 to 1.35$) 0.76$ $120 / 8796 \quad 77 / 5713 \quad 0 \quad$ RR (fixed), $95 \%$ CI $\quad 0.91$ (0.68 to 1.22$) \quad 0.53$

$563 / 33416 \quad 499 / 31501 \quad 37 \quad$ RR (fixed), $95 \%$ CI $\quad 1.08$ (0.96 to 1.22$) \quad 0.20$ $858 / 35961 \quad 885 / 34245 \quad 0 \quad$ RR (fixed), 95\% CI $\quad 0.92$ (0.84 to 1.01$) \quad 0.10$ $426 / 32230 \quad 427 / 32253 \quad 0 \quad$ RR (fixed), $95 \%$ CI $\quad 1.00$ (0.88 to 1.14$) 1.00$

$733 / 43925 \quad 640 / 42275 \quad 69 \quad$ RR (random), 95\% CI 1.06 (0.86 to 1.31$) \quad 0.58$ $366 / 11814 \quad 379 / 11667 \quad 0 \quad \mathrm{RR}$ (random), 95\% CI 0.96 (0.84 to 1.11 ) 0.61 $525 / 30889550 / 28907 \quad 24 \quad$ RR (random), $95 \%$ CI 0.88 (0.76 to 1.03 ) 0.10 $\begin{array}{lllllll}2 / 648 & 4 / 643 & 0 & \text { RR (random), } 95 \% \text { CI } & 0.56 & \text { (0.12 to } 2.66) & 0.47\end{array}$ $32 / 1140 \quad 35 / 1139 \quad 0 \quad$ RR (random), $95 \%$ CI 0.91 (0.56 to 1.45 ) 0.68

$3997 / 85515 \quad 4127 / 85652 \quad 0 \quad$ RR (fixed), $95 \%$ CI $\quad 0.97$ (0.93 to 1.01$) 0.16$ $440 / 13043 \quad 460 / 13009 \quad 0 \quad$ RR (fixed), $95 \%$ CI $\quad 0.94$ (0.83 to 1.07$) 0.36$ $1190 / 11435980 / 8342 \quad 13$ RR (fixed), $95 \%$ CI $\quad 0.94$ (0.86 to 1.01$) \quad 0.11$

$2432 / 36741 \quad 2154 / 34270 \quad 60 \quad$ RR (random), $95 \%$ CI 0.97 (0.88 to 1.08 ) 0.63 $1967 / 29594 \quad 1904 / 27883 \quad 0 \quad$ RR (random), $95 \%$ CI 0.96 (0.90 to 1.02$) \quad 0.18$ $826 / 30971 \quad 869 / 30976 \quad 0 \quad$ RR (random), 95\% CI 0.95 (0.87 to 1.04 ) 0.29

$1830 / 45600 \quad 1700 / 43950 \quad 46 \quad$ RR (fixed), 95\% CI $\quad 1.00$ (0.93 to 1.06$) 0.90$ $1219 / 11811 \quad 1300 / 11667 \quad 0 \quad$ RR (fixed), 95\% CI 0.94 (0.87 to 1.01$) \quad 0.08$ $\begin{array}{lllll}2131 / 37760 & 2067 / 36570 & 0 & \text { RR (fixed), } 95 \% \text { CI } \quad 0.96(0.91 \text { to } 1.02) & 0.22\end{array}$ $19 / 1221 \quad 14 / 839 \quad 0 \quad$ RR (fixed), $95 \%$ CI $\quad 1.10(0.55$ to 2.20$) 0.79$

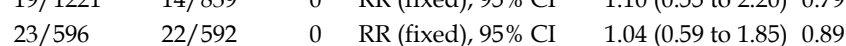

$\oplus \oplus \oplus \oplus$ High $\oplus \oplus \oplus \oplus$ High $\oplus \oplus \oplus \oplus$ High

$\oplus \oplus \oplus \oplus$ High $\oplus \oplus \oplus \oplus$ High $\oplus \oplus \oplus \oplus$ High

$\oplus \oplus \oplus \mathrm{O}$ Moderate $\oplus \oplus \oplus \oplus$ High $\oplus \oplus \oplus \oplus$ High $\oplus \oplus \oplus \oplus$ High $\oplus \oplus \oplus \oplus$ High

$\oplus \oplus \oplus \oplus$ High $\oplus \oplus \oplus \oplus$ High $\oplus \oplus \oplus \oplus$ High

$\oplus \oplus \oplus \mathrm{O}$ Moderate $\oplus \oplus \oplus \oplus$ High $\oplus \oplus \oplus \oplus$ High

$\oplus \oplus \oplus \oplus$ High $\oplus \oplus \oplus \oplus$ High $\oplus \oplus \oplus \oplus$ High $\oplus \oplus \oplus \oplus$ High $\oplus \oplus \oplus \oplus$ High

$3311 / 44813 \quad 3252 / 4485260 \quad$ RR (random), 95\% CI 1.01 (0.93 to 1.10 ) 0.78 $\begin{array}{lllll}932 / 41091 & 983 / 41116 & 0 & \text { RR (random), 95\% CI } 0.95 \text { (0.87 to } 1.04 \text { ) } 0.24\end{array}$ $2340 / 47361 \quad 2433 / 47392 \quad 0 \quad$ RR (random), $95 \%$ CI 0.96 (0.91 to 1.02 ) 0.16

$\oplus \oplus \oplus \mathrm{O}$ Moderate $\oplus \oplus \oplus \oplus$ High $\oplus \oplus \oplus \oplus$ High
$1256 / 71279 \quad 876 / 71455 \quad 11 \quad$ RR (fixed), $95 \%$ CI $54 / 11441 \quad 34 / 11412 \quad 0 \quad$ RR (fixed), $95 \%$ CI
1.44 (1.32 to 1.57$)<0.00001^{*} \oplus \oplus \oplus \oplus$ High 1.58 (1.03 to 2.42 ) $0.04^{*} \quad \oplus \oplus \oplus \oplus$ High 


\begin{tabular}{|c|c|c|c|c|c|c|c|c|}
\hline \multirow[t]{2}{*}{ Outcomes } & \multirow{2}{*}{$\begin{array}{l}\text { No. of } \\
\text { Studies }\end{array}$} & \multicolumn{2}{|c|}{ Events/no. of patients } & \multirow[t]{2}{*}{$I^{2}$} & \multirow[t]{2}{*}{ Statistical method } & \multirow{2}{*}{$\begin{array}{l}\text { Relative risk } \\
(95 \% \mathrm{CI})\end{array}$} & \multirow[t]{2}{*}{$P$ value } & \multirow{2}{*}{$\begin{array}{l}\text { Quality of the } \\
\text { evidence (GRADE) }\end{array}$} \\
\hline & & Aspirin & No Aspirin & & & & & \\
\hline$>300 \mathrm{mg} / \mathrm{d}$ & 3 & $76 / 15215$ & $41 / 13116$ & 0 & RR (fixed), 95\% CI & 1.49 (1.02 to 2.18$)$ & $0.04^{*}$ & $\oplus \oplus \oplus \oplus$ High \\
\hline \multicolumn{9}{|c|}{ Follow-up duration } \\
\hline $1-5$ years & 12 & $801 / 58249$ & $529 / 58016$ & 0 & RR (fixed), 95\% CI & 1.51 (1.35 to 1.69$)$ & $<0.00001^{*}$ & $\oplus \oplus \oplus \oplus$ High \\
\hline $5-10$ years & 6 & $486 / 27602$ & $358 / 25917$ & 0 & RR (fixed), 95\% CI & 1.34 (1.17 to 1.53$)$ & $<0.0001^{*}$ & $\oplus \oplus \oplus \oplus$ High \\
\hline$>10$ years & 3 & $186 / 32230$ & $136 / 32253$ & 30 & RR (fixed), 95\% CI & 1.37 (1.10 to 1.71$)$ & $0.005^{*}$ & $\oplus \oplus \oplus \oplus$ High \\
\hline \multicolumn{9}{|c|}{ Total bleeding events } \\
\hline \multicolumn{9}{|l|}{ Dose of aspirin } \\
\hline$\leq 100 \mathrm{mg} / \mathrm{d}$ & 11 & $850 / 43659$ & $523 / 43744$ & 40 & RR (random), 95\% CI & 1.61 (1.37 to 1.89$)$ & $<0.00001^{*}$ & $\oplus \oplus \oplus \oplus$ High \\
\hline $100-300 \mathrm{mg} / \mathrm{d}$ & 4 & $3079 / 12719$ & $2306 / 12693$ & 40 & RR (random), 95\% CI & 1.45 (1.13 to 1.85$)$ & $0.003^{*}$ & $\oplus \oplus \oplus \oplus$ High \\
\hline$>300 \mathrm{mg} / \mathrm{d}$ & 6 & $331 / 8765$ & $123 / 5686$ & 76 & RR (random), 95\% CI & 1.72 (1.06 to 2.78 ) & $0.03^{*}$ & $\oplus \oplus \oplus \mathrm{O}$ Moderate \\
\hline \multicolumn{9}{|c|}{ Follow-up duration } \\
\hline $1-5$ years & 13 & $806 / 20952$ & $406 / 19618$ & 41 & RR (fixed), 95\% CI & 1.77 (1.57 to 1.99$)$ & $<0.00001^{*}$ & $\oplus \oplus \oplus \oplus$ High \\
\hline $5-10$ years & 4 & $3110 / 23919$ & $2332 / 19658$ & 26 & RR (fixed), 95\% CI & 1.33 (1.26 to 1.39$)$ & $<0.00001^{*}$ & $\oplus \oplus \oplus \oplus$ High \\
\hline$>10$ years & 2 & $207 / 21193$ & $158 / 21219$ & 0 & RR (fixed), 95\% CI & 1.32 (1.07 to 1.62$)$ & $0.008^{*}$ & $\oplus \oplus \oplus \oplus$ High \\
\hline
\end{tabular}

Patient or population: Participants without pre-existing cancer;

Setting: Randomized clinical trials comparing aspirin versus no aspirin and reporting cancer outcomes, long-term aspirin use for the primary prevention of cancer? Intervention: Aspirin; Comparison: No aspirin

Abbreviations: CVD, cardiovascular diseases; DM, diabetes mellitus; RCT, randomized controlled trial; RD, risk difference; RR, risk ratio; CI, confidence interval;

* Statistically significant.

\section{Subgroup analyses of total cancer incidence, cancer mortality and all-cause mortality based on follow-up duration}

There was no significant reduction in total cancer incidence with aspirin use when different follow-up durations were evaluated $[1-5$ years $(\mathrm{RR}=0.99,95 \%$ CI: 0.93 to $1.05, P=0.65)$; $5-10$ years $(\mathrm{RR}=1.01,95 \%$ CI: 0.90 to $1.14, P=0.82)$; $>10$ years $(\mathrm{RR}=1.00,95 \% \mathrm{CI}$ : 0.94 to $1.06, P=0.96$ )] (Table 2; Supplementary Figure S6A).

For total cancer mortality or all-cause mortality, the stratified meta-analysis showed similar results; aspirin use was not associated with either total cancer mortality [ $1-5$ years ( $R R=1.08,95 \%$ CI: 0.96 to $1.22, P$ $=0.20) ; 5-10$ years $(\mathrm{RR}=0.92,95 \% \mathrm{CI}: 0.84$ to $1.01, P=$ $0.10)$; $>10$ years $(\mathrm{RR}=1.00,95 \% \mathrm{CI}$ : $(0.88$ to $1.14, P=$ 1.00)] (Table 2; Supplementary Figure S6B) or all-cause mortality [1-5 years ( $R R=0.97,95 \%$ CI: 0.88 to $1.08, P=0.63) ; 5-10$ years ( $\mathrm{RR}=0.96,95 \% \mathrm{CI}: 0.90$ to $1.02, P=0.18)$; or $>10$ years (RR $=0.95,95 \% \mathrm{CI}: 0.87$ to 1.04, $P=0.29$ )] (Table 2; Supplementary Figure S6C).

The meta-regression analysis indicated that total cancer incidence, cancer mortality or all-cause mortality did not vary significantly with respect to follow-up duration (from 1-5 years to $>10$ years) (Supplementary Figure S7).

A subgroup analysis was also conducted by only including the RCTs that used an aspirin dose $\leq 100$ $\mathrm{mg} / \mathrm{d}$ for $>5$ years. This analysis showed that using a low dose of aspirin $(\leq 100 \mathrm{mg} / \mathrm{d})$ for more than five years did not result in a lower total cancer incidence $(\mathrm{RR}=1.01,95 \% \mathrm{CI}: 0.93$ to $1.10, P=0.78)$, total cancer mortality (RR $=0.96,95 \% \mathrm{CI}: 0.87$ to $1.04, P=0.24)$ or all-cause mortality ( $R R=0.96,95 \% \mathrm{CI}: 0.91$ to $1.02, P=$ 0.16) (Table 2; Supplementary Figure S8).

\section{Subgroup analyses of total cancer incidence, cancer mortality and all-cause mortality based on study population}

Aspirin did not decrease the total cancer incidence in the different subgroups of participants, including the healthy population $(\mathrm{RR}=1.02,95 \% \mathrm{CI}$ : 0.97 to $1.07, P=0.54$ ), patients with diabetes mellitus (RR $=0.95,95 \%$ CI: 0.84 to $1.08, P=0.42$ ), participants with CVD or at increased risk of CVD (RR $=1.04,95 \%$ CI: 0.92 to $1.19, P=0.50$ ), individuals at increased risk of cancer $(\mathrm{RR}=1.00,95 \% \mathrm{CI}$ : 0.66 to $1.54, P=0.99)$, or patients with peripheral arterial disease or venous thromboembolism $(\mathrm{RR}=0.81,95 \% \mathrm{CI}: 0.60$ to $1.10, P=$ 0.18) (Table 2; Supplementary Figure S9A).

Subgroup analyses also showed that the risks of cancer mortality or all-cause mortality in the above subgroups were not reduced by long-term aspirin use (all $P>0.05$ ) (Table 2; Supplementary Figure S9B and S9C).

\section{Subgroup analyses of bleeding events based on aspirin dose}

The summary estimates indicated that compared with no aspirin, all three different daily doses of aspirin significantly increased the risk of major bleeding [ $\leq 100 \mathrm{mg}(\mathrm{RR}=1.44,95 \% \mathrm{CI}: 1.32$ to $1.57, P<$ $0.00001), 100-300 \mathrm{mg}$ (RR $=1.58,95 \% \mathrm{CI}: 1.03$ to $2.42, P$ $=0.04)$, or $>300 \mathrm{mg}(\mathrm{RR}=1.49,95 \% \mathrm{CI}: 1.02$ to $2.18, P$ $=0.04)$ ( Table 2; Figure S10A).

For total bleeding events, the results were similar, and the risk was significantly increased in the three subgroups treated with different daily doses of aspirin $[\leq 100 \mathrm{mg}$ (RR $=1.61,95 \% \mathrm{CI}: 1.37$ to $1.89, P<$ $0.00001) ; 100-300 \mathrm{mg}$ (RR $=1.45,95 \% \mathrm{CI}: 1.13$ to $1.85, P$ $=0.003) ;$ or $>300 \mathrm{mg}(\mathrm{RR}=1.72,95 \% \mathrm{CI}: 1.06$ to $2.78, P$ $=0.03)]$ (Table 2; Figure S10B). 
A

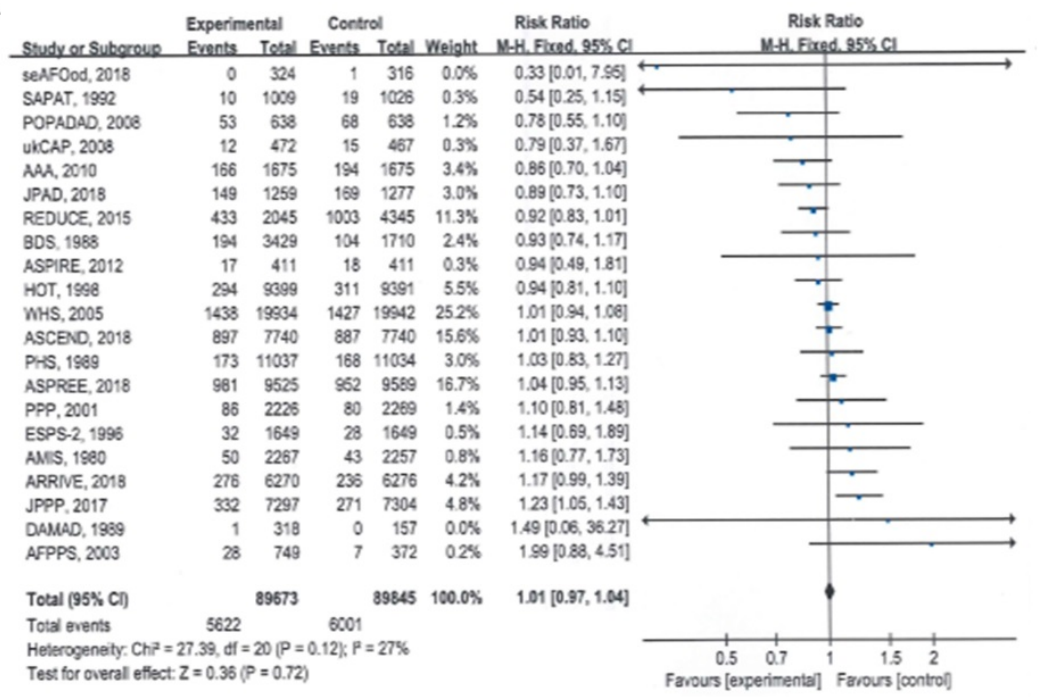

B

\begin{tabular}{|c|c|c|c|c|c|c|c|c|}
\hline \multirow{3}{*}{ Stucty or Subgrove } & \multicolumn{2}{|c|}{ Experimental } & \multicolumn{2}{|c|}{ Control } & \multirow{2}{*}{\multicolumn{2}{|c|}{$\begin{array}{l}\text { Risk Ratio } \\
\text { Weight } \quad \text { N-H. Fixed, } 25 \% \mathrm{Cl}\end{array}$}} & \multirow{2}{*}{\multicolumn{2}{|c|}{$\begin{array}{l}\text { Risk Ratio } \\
\text { N.H. Fixed. } 95 \mathrm{~K}, \mathrm{Cl}\end{array}$}} \\
\hline & Events & Total & Events & Total & & & & \\
\hline & 78 & 1675 & 90 & 1675 & $5.6 \%$ & $0.87[0.64,1.16]$ & & \\
\hline ASCEND, 2018 & 309 & 7740 & 315 & 7740 & $19.7 \%$ & $0.98[0.84,1.14]$ & & + \\
\hline ASPIRE, 2012 & 6 & 411 & 4 & 411 & $0.2 \%$ & $1.50[0.43,5.28]$ & & \\
\hline ASPREE, 2018 & 295 & 9525 & 227 & 9599 & $14.1 \%$ & $1.31[1.10,1.55]$ & & - \\
\hline BDS, 1968 & 75 & 3429 & 46 & 1710 & $3.8 \%$ & $0.81[0.57,1.17]$ & & \\
\hline COPA, 1976 & 1 & 758 & 3 & $m 1$ & 0.25 & $0.34[0.04,3.25]$ & & \\
\hline CUPS, 2007 & 2 & 185 & 0 & 181 & $0.0 \%$ & $4.89,0.24,101.21]$ & & \\
\hline DAMAD, 1989 & 1 & 318 & 0 & 157 & $0.0 \%$ & $1.49[0.06,36.27]$ & & \\
\hline EAFT, 1993 & 10 & 404 & 12 & 378 & $0.8 x$ & $0.78[0.34,1.78]$ & & - \\
\hline ESPS-2, 1996 & 19 & 1649 & 24 & 1649 & $1.5 \%$ & $0.79[0.44,1.44]$ & & 一 \\
\hline ETORS, 1992 & 16 & 1856 & 14 & 1855 & $0.9 \%$ & $1.14[0.56,2.33]$ & & \\
\hline HOT, 1998 & 108 & 9399 & 105 & 9391 & $6.6 \%$ & $1.03[0.79,1.34]$ & & t \\
\hline JPAD, 2008 & 15 & 1262 & 19 & 1277 & $1.2 \%$ & $0.80[0.41,1.57]$ & & \\
\hline JPPP, 2017 & 134 & 7297 & 125 & 7304 & $7.8 \%$ & $1.07[0.84,1.37]$ & & - \\
\hline PARIS, 1960 & 16 & 1620 & 1 & 406 & $0.1 \%$ & $4.01[0.53,30.15]$ & & \\
\hline PHS, 1969 & 79 & 11037 & 68 & 11034 & $4.2 \%$ & $1.16[0.84,1.60]$ & & \\
\hline POPADAD, 2008 & 25 & 638 & 31 & 638 & $1.9 \%$ & $0.81[0.48,1.35]$ & & - \\
\hline PPP, 2001 & 31 & 2226 & 20 & 2269 & $1.8 \%$ & $1.09[0.66,1.80]$ & & \\
\hline $\begin{array}{l}\text { SALT, } 1991 \\
\text { SAPAT, } 1992\end{array}$ & $\begin{array}{l}10 \\
10\end{array}$ & $\begin{array}{r}676 \\
1019\end{array}$ & $\begin{array}{l}15 \\
19\end{array}$ & $\begin{array}{r}684 \\
1026\end{array}$ & $\begin{array}{l}0.9 \mathrm{x} \\
1.2 \mathrm{x}\end{array}$ & $\begin{array}{l}0.67[0.31,1.49] \\
0.53[0.25,1.13]\end{array}$ & & \\
\hline $\begin{array}{l}\text { SAPAT, } 1992 \\
\text { seAFOOd, } 2018\end{array}$ & 0 & 324 & 1 & 316 & $0.1 \%$ & $0.33[0.01,7.95]$ & & \\
\hline TPT. 1998 & 87 & 2545 & 104 & 2540 & $6.5 \%$ & $0.83[0.63,1.10]$ & $\longrightarrow$ & \\
\hline UK-TLA, 1991 & 21 & 1621 & 23 & 814 & $1.9 \%$ & $0.46[0.26,0.82]$ & & \\
\hline $\begin{array}{l}\text { UKCAP, } 2008 \\
\text { WHS, } 2005\end{array}$ & $\begin{array}{r}2 \\
284\end{array}$ & $\begin{array}{r}472 \\
19934\end{array}$ & $\begin{array}{r}3 \\
299\end{array}$ & $\begin{array}{r}467 \\
19942\end{array}$ & $\begin{array}{r}0.2 \% \\
18.7 \%\end{array}$ & $\begin{array}{l}0.66[0.11,3.93] \\
0.95[0.81,1.12]\end{array}$ & & \\
\hline Total (95\% CI) & & 88020 & & 84224 & $100.0 \%$ & $1.00[0.93,1.07]$ & & \\
\hline Total everts & 1634 & & 1577 & & & & & \\
\hline $\begin{array}{l}\text { Helerogeneity: Cri2 = } \\
\text { Test for overal effect }\end{array}$ & $\begin{array}{l}32.49, \mathrm{df}= \\
\mathrm{Z}=0.13 \mathrm{~F}\end{array}$ & $\begin{array}{l}24(P=C \\
P=0.90)\end{array}$ & & & & & $\underset{\text { Fav }}{0.05}$ & \\
\hline
\end{tabular}

C

$\begin{array}{lll}\text { Experimental Control } & \text { Risk Ratio } \\ \text { Study or Subgrove Events Total Events Total Welght M-H. Fixad. 25s }\end{array}$ $\begin{array}{llllllll}\text { AAA, } 2010 & 176 & 1675 & 186 & 1675 & 3.7 \% & 0.96[0.78,1.15]\end{array}$ $\begin{array}{lrrrrrr}\text { AFPPS, 2003 } & 7 & 749 & 3 & 372 & 0.1 \% & 0.96[0.78,1.15] \\ \text { AMS, } 1990.30,4.46]\end{array}$ $\begin{array}{lllllll}\text { AMSS, } 1980 & 245 & 2267 & 219 & 2257 & 4.38 & 1.11[0.94,1.32]\end{array}$ \begin{tabular}{lllllll} 
ARRIVE, 2018 & 160 & 6270 & 161 & 6276 & $3.3 \%$ & $1.11[0.94,1.32]$ \\
\hline & & $0.99[0.80,1.23]$
\end{tabular} $\begin{array}{lllllll}\text { ASCEND, } 2018 & 748 & 7740 & 792 & 7740 & 15.7 \% & 0.94[0.86,1.04]\end{array}$ $\begin{array}{lrlrllll}\text { ASPIRE, } 2012 & 16 & 411 & 18 & 411 & 0.4 \% & 0.89[0.46,1.72]\end{array}$ $\begin{array}{lllllll}\text { BOS. 1988 } & 558 & 9525 & 494 & 9689 & 9.7 \% & 1.14[1.01,1.28]\end{array}$

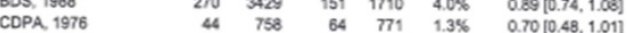
$\begin{array}{llllllll}\text { CLIPS, } 2007 & 7 & 185 & 4 & 181 & 0.1 \% & 1.71[0.51 .575]\end{array}$ $\begin{array}{lllllll}\text { DAMAD, } 1989 & 3 & 318 & 3 & 157 & 0.1 \% & 0.49[0.10,2.42]\end{array}$ $\begin{array}{lrrrrrr}\text { EAFT, } 1983 & 102 & 404 & 99 & 378 & 2.0 \% & 0.96[0.76,1.22]\end{array}$ $\begin{array}{llllllll}\text { ESPS-2, } 1996 & 182 & 1649 & 102 & 1649 & 2006 & 178[1.41,205]\end{array}$ $\begin{array}{lllllll}\text { ETDRS, } 1992 & 300 & 1856 & 366 & 1955 & 7.28 & 0.78[1.41,2.25]\end{array}$ $\begin{array}{lllllll}\text { HOT, } 1996 & 284 & 9399 & 305 & 9391 & 6.04 & 0.93[0.81,1.06]\end{array}$ $\begin{array}{lrrrrrrr}\text { JPAD, } 2008 & 34 & 1259 & 38 & 1277 & 0.7 \% & 0.93[0.79,1.09]\end{array}$ $\begin{array}{llllllll}\text { JPPP, } 2017 & 303 & 7297 & 308 & 7304 & 6.1 \% & 0.91[0.58,1.43]\end{array}$ $\begin{array}{lllllll}\text { PARIS, } 1950 & 172 & 1620 & 52 & 406 & 1.6 \% & 0.93[0.86,1.15]\end{array}$ $\begin{array}{llllllll}\text { PHS, } 1989 & 217 & 11037 & 227 & 11034 & 4.54 & 0.83[0.62,1.11]\end{array}$ $\begin{array}{llllllll}\text { POPADAD, } 2008 & 94 & 638 & 101 & 638 & 2.0 \% & 0.93[0.72,1.121]\end{array}$ $\begin{array}{llllllll}\text { PPP. } 2001 & 62 & 2026 & 78 & 2269 & 1.58 & 0.93[0.72,1.11]\end{array}$ $\begin{array}{llllll}61 & 676 & 78 & 684 & 1.48 & 0.81[0.58,1.13\end{array}$ $\begin{array}{llllllll}\text { SAPAT, } 1992 & 82 & 1019 & 106 & 1026 & 2.48 & 0.89[0.64,1.24]\end{array}$ $\begin{array}{lrrrrrr}\text { seAFOod, } 2018 & 0 & 324 & 1 & 316 & 0.0 \% & 0.33[0.01,7.96]\end{array}$ $\begin{array}{llllllll}\text { TPT, } 1998 & 216 & 2545 & 205 & 2540 & 4.1 \% & 1.05[0.88,1.26]\end{array}$ $\begin{array}{lllllll}\text { UK.TIA, } 1991 & 221 & 1621 & 122 & 814 & 3.2 \% & 0.91[0.74,1.12]\end{array}$ $\begin{array}{lrrrrrr}\text { UKCAP, } 2008 & 12 & 472 & 11 & 467 & 0.2 \% & 1.08[0.48,2.42]\end{array}$ $\begin{array}{rrrrrr}\text { Total (95\% Cl) } & 97303 & 93129 & 100.0 \% & 0.98[0.94,1.02]\end{array}$ Total events $5225 \quad 4927$ Test for overal effect $Z=1.01(P=0.31)$

Favours lexperimental Favours loortrol

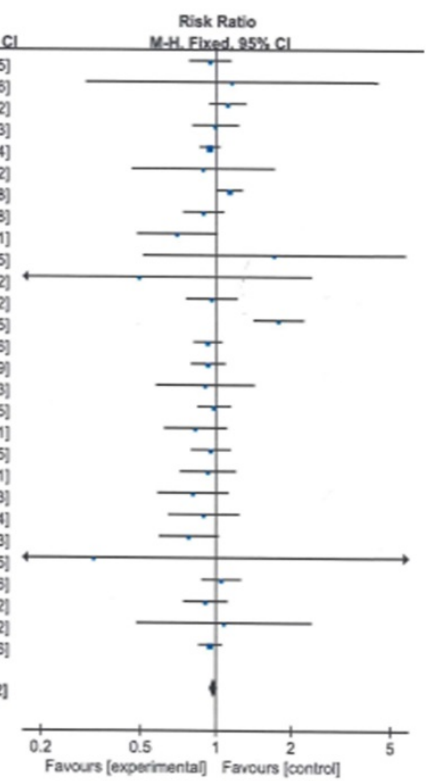

Figure 1. Forest plots showing that long-term aspirin use was not associated with significant reductions in total cancer incidence, total cancer mortality or all-cause mortality. A) Total cancer incidence, B) total cancer mortality, C) all-cause mortality. 
A

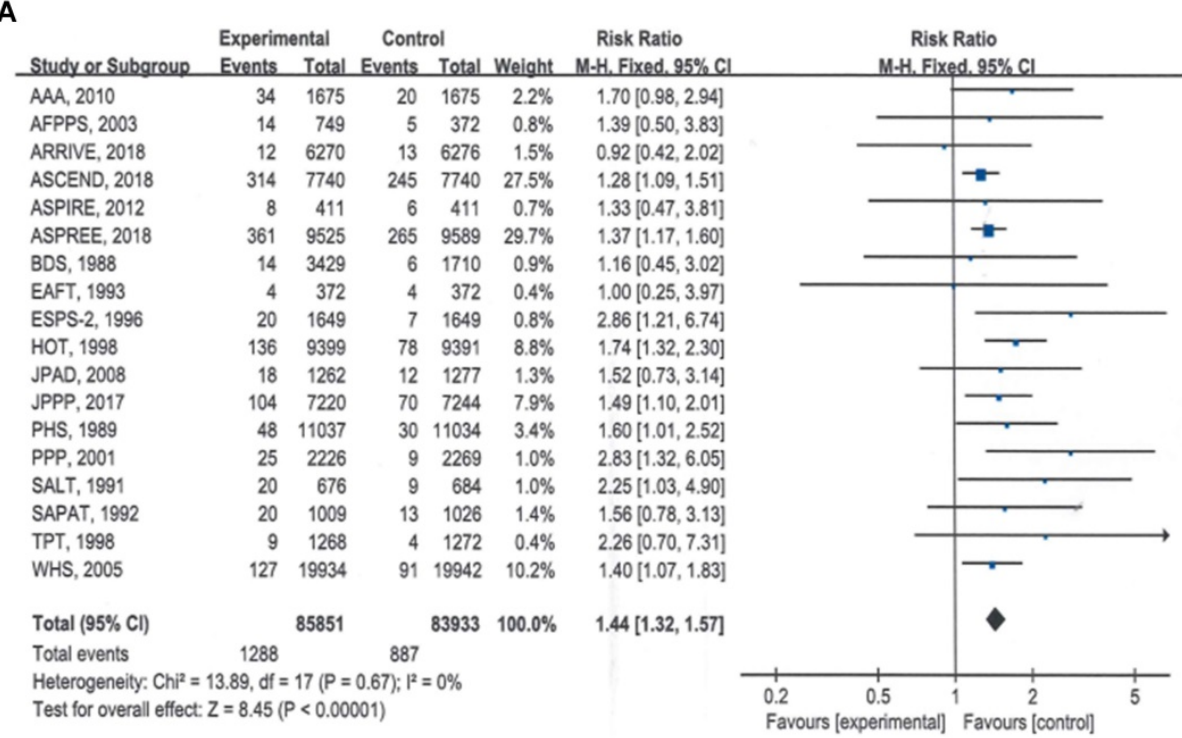

B

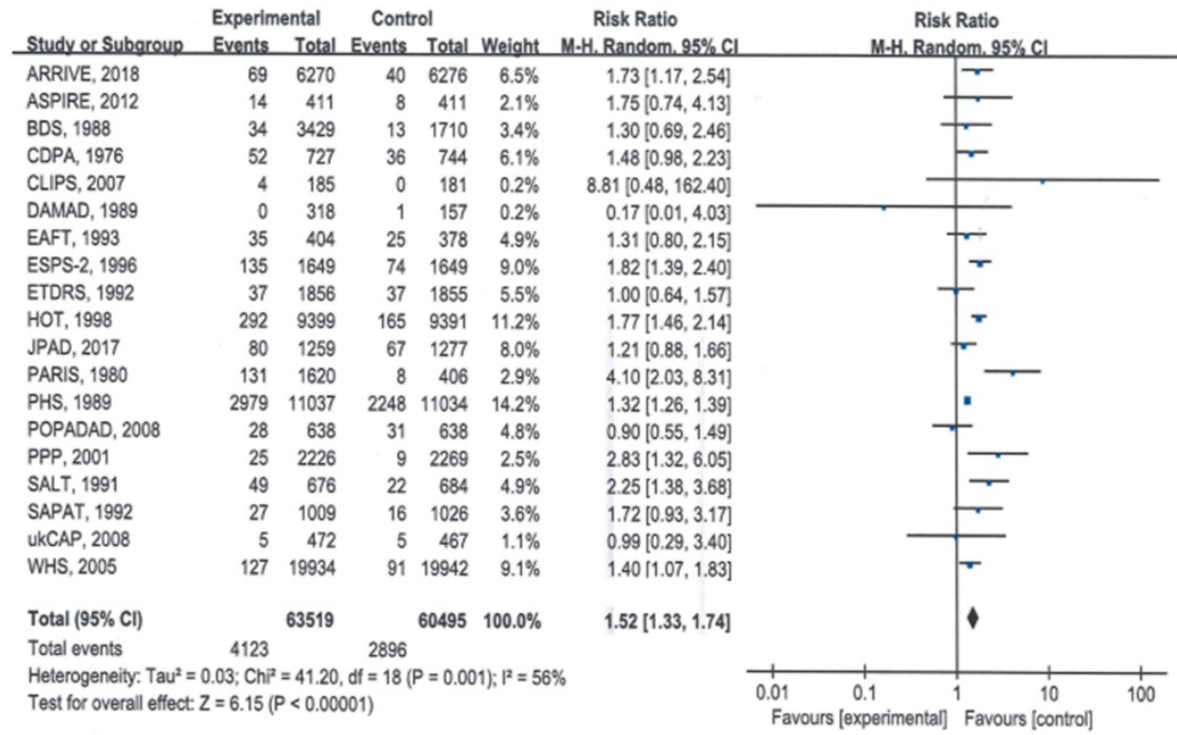

Figure 2. Forest plots showing that the risks of major bleeding and all bleeding events were significantly higher with aspirin than with placebo. A) Major bleeding events, B) total bleeding events.

\section{Subgroup analyses of bleeding events based on follow-up duration}

Subgroup analyses based on follow-up duration showed that the risk of major bleeding and total bleeding events significantly increased after three different follow-up durations (all $P<0.05$ ) (Table 2; Supplementary Table 2 and Supplementary Figure S11A, S11B).

\section{Sensitivity analyses and trial sequential analysis}

Generally, there was good homogeneity among the included clinical trials. In particular, the above subgroup analysis results based on the daily dose of aspirin, follow-up duration, and study populations confirmed the robustness of the findings.

With regard to cancer incidence, the primary outcome, the pooled data showed that aspirin use did not significantly decrease the total cancer incidence. The results were similar when the sensitivity analyses were based on study quality (when only double-blind RCTs were selected) (RR $=1.00,95 \%$ CI: 0.96 to $1.04, P$ $=0.96)$, study sample size $(\geq 2,000$ subjects in each group) $(\mathrm{RR}=1.03,95 \% \mathrm{CI}$ : 0.99 to $1.07, P=0.10)$, and publication year (studies published since the year 2000 $)(\mathrm{RR}=1.01,95 \% \mathrm{CI}: 0.97$ to $1.05, P=0.55)$ and when studies that enrolled participants with increased risk of cancer were excluded $(R R=1.00$, 95\% CI: 0.97 to $1.04, P=0.31$ ) (Supplementary Table $3)$. 
Trial sequential analysis indicated that aspirin was not significantly superior to no aspirin, and the cumulative sample size of all the RCTs reached the required information size (RIS) needed for a conclusive and reliable meta-analysis (Supplementary Figure S12), suggesting that the findings of the meta-analysis were robust for the total cancer incidence outcome. The meta-regression analysis showed that the total cancer incidence did not vary significantly with respect to daily dose of aspirin (from $\leq 100 \mathrm{mg}$ to $>300 \mathrm{mg}$ ) [LogOR $=0.0215-0.0025$ daily dose, $(\mathrm{u}=0.31, P=0.96)]$, or follow-up duration (from 1-5 years to $>10$ years) $[\mathrm{LogOR}=0.0057-0.0043$ Follow-up duration, $\mathrm{u}=0.11, P=0.91]$ (Supplementary Figure S5A, S7A).

For the total cancer mortality, all-cause mortality, major bleeding, and total bleeding events, the sensitivity and subgroup analyses showed similar results.

\section{Quality of evidence and publication bias}

In the 29 included RCTs, 25 were double-blinded trials with overall low methodological bias risk. All available RCTs had large sample sizes, from 475 to 39,876 individuals. For the primary outcome and most of the secondary outcomes, the results had good robustness. Heterogeneity was present in a minority $(7 / 53)$ of the outcomes, and the quality of evidence was downgraded by one level (total bleeding events, total cancer incidence after a follow-up of 5-10 years and in populations at increased risk of CVD, etc.). According to the GRADE guidelines, the quality of evidence for the outcomes measured was moderate to high, and majority were of high quality (Table 2; Supplementary Table S 2).

There was no evidence of publication bias for total cancer incidence, the primary outcome (Egger's test $P=0.348$ ) (Supplementary Figure S13).

\section{Discussion}

The results of previous pooled analyses and meta-analyses of studies of long-term aspirin use for the primary prevention of cancer were inconsistent; most of them showed that aspirin had a substantial net benefit for cancer primary prevention $[8,11,17$, 70], but a few demonstrated that aspirin was not associated with a reduction in the cancer outcomes $[12,18,71]$. The discrepancies in the results might be caused by the varied inclusion criteria used in the different analyses. Most of the previous meta-analysis included observational and/or cohort studies [11, 12, 16-18], which undermined the strength of the evidence regarding the association between aspirin use and cancer incidence or mortality.

Evidence from good-quality meta-analyses of
RCTs is at the top of the evidence hierarchy, but there were very limited meta-analyses of RCTs evaluating the effect of long-term aspirin use on cancer incidence or mortality, and almost all of them only included a primary CVD prevention population [12, 13, 22]. A recent meta-analysis of RCTs assessed the overall effect of aspirin on cancer outcomes [71]; however, many eligible RCTs, including some new trials such as ARRIVE, JPPP, etc., were not included [14, 15]. In addition, two included trials were duplicated $[53,55]$, which might have weakened the strength of the evidence of the meta-analysis [72]. Therefore, it was necessary to conduct an updated systematic review of all eligible RCTs to further evaluate the overall effect of long-term aspirin use on cancer outcomes.

In our study, 29 eligible RCTs that randomized 200,679 participants were included. All RCTs comparing aspirin use to no aspirin use in participants without pre-existing cancer that reported cancer outcomes were selected. To the best of our knowledge, our meta-analysis included the largest number of relevant RCTs and participants, and it is the first comprehensive subgroup meta-analysis of long-term aspirin use for cancer primary prevention based on aspirin dose, follow-up duration, and study populations, which are considered potential modifiers of the effects of aspirin on cancer outcomes. Both the USPSTF and a UK panel called for more research into the effect of long-term aspirin use on cancer primary prevention according to a range of doses and by subgroups, including baseline cancer risk, or comorbid conditions, etc.[12, 13, 18, 73] Though the existing research in this field is far from enough, the findings of the present study may add some evidence regarding the variation in the effects of aspirin use on cancer outcomes by aspirin dose, follow-up duration, or different populations.

\section{Effect of aspirin on total cancer incidence, cancer mortality, and all-cause mortality}

Our data indicated that, compared with no aspirin, long-term aspirin use did not result in a significantly lower risk of total cancer incidence $(P=$ $0.75)$, cancer mortality $(P=0.81)$, or all-cause mortality $(P=0.27)$. The results clearly demonstrated that the current practice of prescribing aspirin as a chemopreventive agent for the primary prevention of cancer brought no benefit to the individuals who underwent aspirin therapy. According to the GRADE guidelines, the quality of evidence for the cancer outcomes (total cancer incidence and mortality) in our study was high.

Trial sequential analysis of total cancer incidence, the primary endpoint, indicated that the use of aspirin in the experimental group was not 
superior to the intervention (no aspirin) in the control group and that the cumulative sample size of all included RCTs reached the required size for a conclusive and reliable meta-analysis.

\section{Association between aspirin dose, follow-up duration and cancer outcomes}

Many studies have shown that long-term aspirin use (especially low-dose aspirin use) reduced the risk of developing and dying from cancer and that the benefit increased with the duration of treatment $[8,9$, 70, 74]. A pooled analysis of six CVD primary prevention studies indicated that daily low-dose aspirin reduced the risk of cancer and that the effect was greater for those who received treatment for at least 5 years [8]. A previous meta-analysis including 218 observational studies found that taking a daily low-dose of $75-100 \mathrm{mg}$ for at least five years dramatically reduced the risks of cancer morbidity and mortality [11].

In our study, subgroup analyses based on aspirin dose or follow-up duration showed that different daily doses of aspirin $(\leq 100 \mathrm{mg}, 100-300 \mathrm{mg}$, or $>300$ $\mathrm{mg}$ ) and different follow-up durations (1-5 years, 5-10 years, or $>10$ years) were not associated with a significant reduction in total cancer incidence, cancer mortality or all-cause mortality. The aspirin dose or follow-up duration did not show any impact on the effect of aspirin, which was not greater for those who received low-dose aspirin or who underwent treatment for more than 5 years.

We also performed a subgroup analysis by only including the participants who used low-dose $(\leq 100$ $\mathrm{mg} / \mathrm{d}$ ) aspirin for more than five years. The results showed no significant reduction in total cancer incidence $(P=0.78)$, total cancer mortality $(P=0.33)$ or all-cause mortality $(P=0.16)$ with aspirin use. The results of the meta-regression analyses confirmed the above findings of the subgroup analyses. Several previous studies reported that daily use of low-dose aspirin for at least five years reduced the risk of cancer and cancer mortality $[8,11,74]$, but they were not meta-analyses of RCTs. Our findings differed from theirs.

\section{Aspirin use for cancer primary prevention in different study populations}

Our study stratified the participants by health status and baseline risk of CVD, cancer, or comorbid conditions, etc., to evaluate the impact of the effect of aspirin on different populations [12, 21, 22, 71]. Subgroup analyses based on population showed that the risks of total cancer incidence, cancer mortality or all-cause mortality were not reduced by aspirin use in five different subgroups, including the healthy population, patients with diabetes mellitus, participants with CVD or at increased risk of CVD, individuals with increased risk of cancer, or patients with peripheral arterial disease or venous thromboembolism.

\section{The risk of bleeding events}

Toxic effects are very common in individuals treated with long-term aspirin; bleeding events are the leading side effects. The present meta-analysis showed that long-term aspirin use was associated with a significant increase in the risk of major bleeding and total bleeding events. Even in the individuals who used low-dose aspirin $(\leq 100 \mathrm{mg})$ for a relatively short duration (1-5 years), the bleeding risk was still significantly increased.

\section{Long-term aspirin use for the prevention of specific cancers}

Our data indicated that long-term aspirin use as a primary cancer prevention measure had no benefit; however, aspirin use was associated with a significantly increased bleeding risk. Therefore, the present evidence does not favor the use of aspirin as a primary prevention strategy in the general population or in the above subgroups.

Because we excluded specific populations with familial cancer syndromes (Lynch syndrome, etc.) [75], more studies are needed to evaluate the benefit and risk of aspirin as an anticancer intervention for these populations.

In this study, we only evaluated the effect of long-term aspirin use for overall cancer prevention. We did not evaluate the effect of this intervention on the prevention of specific subtypes of cancer. There seem to be some evidence to support the use of aspirin for the chemoprevention of a few specific cancers, especially colorectal cancer $[22,76]$; more research is needed to further assess the effect of aspirin use on different cancers [21, 77-82].

\section{Limitations}

Our study had some limitations: firstly, although the included trials collected data on cancer outcomes, most of them were designed as RCTs to evaluate aspirin's effect on the cardiovascular system or on non-cancer outcomes (outcomes other than primary cancer prevention). Therefore, some potential confounding factors could have affected the outcomes, thus masking the actual association or falsely demonstrating an association between the aspirin treatment and cancer outcomes.

Second, the cancer rates were much lower than in the setting of CVD or other comorbidities. The sample size needed for primary cancer prevention 
trials is larger, and the study duration must be longer; the sample size or follow-up duration of some of the included RCTs might have been insufficient.

Third, some of the included trials had heterogeneity and potential risk of bias, and the quality of evidence of some outcomes was moderate, thus weakening the trustworthiness and strength of evidence from this systematic review.

Last, individual patient data were not sufficient, and consequently, information for more stratified analyses (e.g., by age, sex, risk factors, cancer type) was limited.

\section{Conclusions}

From the available evidence, our data indicated that compared with no aspirin, the long-term use of aspirin in individuals without pre-existing cancer was not associated with a reduction in total cancer incidence, cancer mortality, or all-cause mortality; however, aspirin use was associated with a significant increase in the risk of bleeding in this population. Therefore, aspirin might not be an appropriate choice for the primary prevention of cancer. Prospective RCTs of the role of aspirin in primary cancer prevention are warranted.

\section{Abbreviations}

CI: confidence interval; CVD: cardiovascular diseases; GRADE: The Grading of Recommendations Assessment Development and Evaluation Working Group Methodology; PRISMA: Preferred Reporting Items for Systematic Reviews and Meta-Analyses; RCT: randomized controlled trial; RD: risk difference; RR: risk ratio; TSA: Trial Sequential Analysis; WHO: World Health Organization.

\section{Supplementary Material}

Supplementary figures and tables. http://www.jcancer.org/v11p6460s1.pdf

\section{Acknowledgments}

\section{Funding}

This study was funded by the Science and Technology Development Fund, Macau SAR (file no. 130/2017/A3, 0099/2018/A3, 0096/2018/A3), the National Natural Science Foundation of China (grant no. 81874380,81672932 and 81730108 ), the Zhejiang Provincial Natural Science Foundation of China for Distinguished Young Scholars (Grant no. LR18H160001), the Zhejiang province science and technology project of TCM (grant no. 2019ZZ016) and the Key Project of Hangzhou Ministry of Science and Technology (grant no. 20162013A07, 20142013A63).

\section{Competing Interests}

The authors have declared that no competing interest exists.

\section{References}

1. Bray F, Ferlay J, Soerjomataram I, Siegel RL, Torre LA, Jemal A. Global cancer statistics 2018: GLOBOCAN estimates of incidence and mortality worldwide for 36 cancers in 185 countries. CA Cancer J Clin. 2018; 68: 394-424.

2. Siegel RL, Miller KD, Jemal A. Cancer statistics, 2019. CA Cancer J Clin. 2019; 69: 7-34.

3. Chen P, Wu Q, Feng J, Yan L, Sun Y, Liu S, et al. Erianin, a novel dibenzyl compound in Dendrobium extract, inhibits lung cancer cell growth and migration via calcium/calmodulin-dependent ferroptosis. Signal Transduct Target Ther. 2020; 5: 51.

4. Chen H, Yao X, Li T, Lam CW, Zhang R, Zhang H, et al. Compound Kushen injection combined with platinum-based chemotherapy for stage III/IV non-small cell lung cancer: A meta-analysis of 37 RCTs following the PRISMA guidelines. J Cancer. 2020; 11: 1883-98.

5. Wu X, Wu Q, Zhou X, Huang J. SphK1 functions downstream of IGF-1 to modulate IGF-1-induced EMT, migration and paclitaxel resistance of A549 cells: A preliminary in vitro study. J Cancer. 2019; 10: 4264-9.

6. WHO. Cancer Prevention. http://www.who.int/cancer/prevention/ en/. Accessed August 15, 2019.

7. Gorin SS, Wang C, Raich P, Bowen DJ, Hay J. Decision making in cancer primary prevention and chemoprevention. Ann Behav Med. 2006; 32: 179-87.

8. Rothwell PM, Fowkes FG, Belch JF, Ogawa H, Warlow CP, Meade TW. Effect of daily aspirin on long-term risk of death due to cancer: analysis of individual patient data from randomised trials. Lancet. 2011; 377: 31-41.

9. Cao $\mathrm{Y}$, Nishihara $\mathrm{R}$, Wu $\mathrm{K}$, Wang $\mathrm{M}$, Ogino $\mathrm{S}$, Willett $\mathrm{WC}$, et al. Population-wide Impact of Long-term Use of Aspirin and the Risk for Cancer. JAMA Oncol. 2016; 2: 762-9.

10. Cuzick J, Thorat MA, Bosetti C, Brown PH, Burn J, Cook NR, et al. Estimates of benefits and harms of prophylactic use of aspirin in the general population. Ann Oncol. 2015; 26: 47-57.

11. Qiao Y, Yang T, Gan Y, Li W, Wang C, Gong Y, et al. Associations between aspirin use and the risk of cancers: a meta-analysis of observational studies. BMC Cancer. 2018; 18: 288.

12. Chubak J, Whitlock EP, Williams SB, Kamineni A, Burda BU, Buist DS, et al. Aspirin for the Prevention of Cancer Incidence and Mortality: Systematic Evidence Reviews for the U.S. Preventive Services Task Force. Ann Intern Med. 2016; 164: 814-25

13. Zheng SL, Roddick AJ. Association of Aspirin Use for Primary Prevention With Cardiovascular Events and Bleeding Events: A Systematic Review and Meta-analysis. JAMA. 2019; 321: 277-87.

14. Gaziano JM, Brotons C, Coppolecchia R, Cricelli C, Darius H, Gorelick PB, et al. Use of aspirin to reduce risk of initial vascular events in patients at moderate risk of cardiovascular disease (ARRIVE): a randomised, double-blind, placebo-controlled trial. Lancet. 2018; 392: 1036-46.

15. McNeil JJ, Nelson MR, Woods RL, Lockery JE, Wolfe R, Reid CM, et al. Effect of Aspirin on All-Cause Mortality in the Healthy Elderly. N Engl J Med. 2018; 379: 1519-28.

16. Lu L, Shi L, Zeng J, Wen Z. Aspirin as a potential modality for the chemoprevention of breast cancer: A dose-response meta-analysis of cohort studies from 857,831 participants. Oncotarget. 2017; 8: 40389-401.

17. Algra AM, Rothwell PM. Effects of regular aspirin on long-term cancer incidence and metastasis: a systematic comparison of evidence from observational studies versus randomised trials. Lancet Oncol. 2012; 13: 518-27.

18. Whitlock EP WS, Burda BU, Feightner A, Beil T. Aspirin Use in Adults: Cancer, All-Cause Mortality, and Harms. A Systematic Evidence Review for the U.S. Preventive Services Task Force. Evidence Synthesis No. 132. AHRQ Publication No. 13-05193-EF-1. Rockville, MD: Agency for Healthcare Research and Quality. September 2015.

19. Veettil SK, Jinatongthai $P$, Nathisuwan $S$, Teerawattanapong N, Ching SM, Lim KG, et al. Efficacy and safety of chemopreventive agents on colorectal cancer incidence and mortality: systematic review and network meta-analysis. Clin Epidemiol. 2018; 10: 1433-45.

20. Luo T, Yan HM, He P, Luo Y, Yang YF, Zheng H. Aspirin use and breast cancer risk: a meta-analysis. Breast Cancer Res Treat. 2012; 131: 581-7.

21. Bibbins-Domingo K, Force USPST. Aspirin Use for the Primary Prevention of Cardiovascular Disease and Colorectal Cancer: U.S. Preventive Services Task Force Recommendation Statement. Ann Intern Med. 2016; 164: 836-45.

22. Force USPST. Aspirin for the prevention of cardiovascular disease: U.S. Preventive Services Task Force recommendation statement. Ann Intern Med. 2009; 150: 396-404

23. Mills EJ, Wu P, Alberton M, Kanters S, Lanas A, Lester R. Low-dose aspirin and cancer mortality: a meta-analysis of randomized trials. Am J Med. 2012; 125: 560-7.

24. Moher D, Liberati A, Tetzlaff J, Altman DG, Group P. Preferred reporting items for systematic reviews and meta-analyses: the PRISMA statement. BMJ. 2009; 339: b2535 
25. Wu Q, Chen H, Yao X, Li T, Xu C, Wang J, et al. Long-term aspirin use for cancer primary prevention: A protocol for updated systematic review and subgroup meta-analysis of randomized clinical trials. Medicine (Baltimore). 2019; 98: e17382.

26. Higgins JGS. Cochrane Handbook for Systematic Reviews of Interventions Version 5.1.0. 2011.

27. Jadad AR, Moore RA, Carroll D, Jenkinson C, Reynolds DJ, Gavaghan DJ, et al. Assessing the quality of reports of randomized clinical trials: is blinding necessary? Control Clin Trials. 1996; 17: 1-12.

28. Zhang YW, Zhang J, Hu JQ, Wen CL, Dai SY, Yang DF, et al. Neuraxial adjuvants for prevention of perioperative shivering during cesarean section: A network meta-analysis following the PRISMA guidelines. World J Clin Cases. 2019; 7: 2287-301.

29. Wang J, Li G, Yu L, Mo T, Wu Q, Zhou Z. Aidi injection plus platinum-based chemotherapy for stage IIIB/IV non-small cell lung cancer: A meta-analysis of 42 RCTs following the PRISMA guidelines. J Ethnopharmacol. 2018; 221: 137-50.

30. Wang X, Liu Z, Sui X, Wu Q, Wang J, Xu C. Elemene injection as adjunctive treatment to platinum-based chemotherapy in patients with stage III/IV non-small cell lung cancer: A meta-analysis following the PRISMA guidelines. Phytomedicine. 2019; 59: 152787.

31. Wu Q, Leung EL. Association of Dietary Fiber and Yogurt Consumption With Lung Cancer Risk. JAMA Oncol. 2020.

32. Wu Q, Lai-Han Leung E. Commentary on Ge et al. "Insomnia and risk of mortality from all-cause, cardiovascular disease, and cancer: Systematic review and meta-analysis of prospective cohort studies". Sleep Med Rev. 2020; 50: 101257.

33. Guo Q, Yang S, Yang D, Zhang N, Li X, Chen T, et al. Differential mRNA expression combined with network pharmacology reveals network effects of Liangxue Tongyu Prescription for acute intracerebral hemorrhagic rats. J Ethnopharmacol. 2019; p: 112231.

34. Wu Q, Li G, Lei WI, Zhou X. The efficacy and safety of tiotropium in Chinese patients with stable chronic obstructive pulmonary disease: a meta-analysis. Respirology. 2009; 14: 666-74

35. Zhou Z, Shen W, Yu L, Xu C, Wu Q. A Chinese patent medicine, Shexiang Baoxin Pill, for Non-ST-elevation acute coronary syndromes: A systematic review. J Ethnopharmacol. 2016; 194: 1130-9.

36. Lin $\mathrm{S}$, An $\mathrm{X}$, Guo $\mathrm{Y}, \mathrm{Gu} J$, Xie $\mathrm{T}$, Wu $\mathrm{Q}$, et al. Meta-Analysis of Astragalus-Containing Traditional Chinese Medicine Combined With Chemotherapy for Colorectal Cancer: Efficacy and Safety to Tumor Response. Front Oncol. 2019; 9: 749.

37. Guyatt G, Oxman AD, Sultan S, Brozek J, Glasziou P, Alonso-Coello P, et al. GRADE guidelines: 11. Making an overall rating of confidence in effect estimates for a single outcome and for all outcomes. J Clin Epidemiol. 2013; 66: 151-7.

38. Egger M, Davey Smith G, Schneider M, Minder C. Bias in meta-analysis detected by a simple, graphical test. BMJ. 1997; 315: 629-34.

39. Thorlund K EJ, Wetterslev J, et al. . User manual for trial sequential analysis (TSA). Copenhagen Trial Unit, Centre for Clinical Intervention Research, Copenhagen, Denmark. 2011; p.1-115.

40. Fowkes FG, Price JF, Stewart MC, Butcher I, Leng GC, Pell AC, et al. Aspirin for prevention of cardiovascular events in a general population screened for a low ankle brachial index: a randomized controlled trial. JAMA. 2010; 303: 841-8.

41. Baron JA, Cole BF, Sandler RS, Haile RW, Ahnen D, Bresalier R, et al. A randomized trial of aspirin to prevent colorectal adenomas. N Engl J Med. 2003; 348: 891-9.

42. [No authors listed] A randomized, controlled trial of aspirin in persons recovered from myocardial infarction. JAMA. 1980; 243(7): 661-9.

43. Group ASC, Bowman L, Mafham M, Wallendszus K, Stevens W, Buck G, et al. Effects of Aspirin for Primary Prevention in Persons with Diabetes Mellitus. N Engl J Med. 2018; 379: 1529-39.

44. Brighton TA, Eikelboom JW, Mann K, Mister R, Gallus A, Ockelford P, et al. Low-dose aspirin for preventing recurrent venous thromboembolism. N Engl J Med. 2012; 367: 1979-87.

45. Peto R, Gray R, Collins R, Wheatley K, Hennekens C, Jamrozik K, et al. Randomised trial of prophylactic daily aspirin in British male doctors. Br Med J (Clin Res Ed). 1988; 296: 313-6.

46. Aspirin in coronary heart disease. The Coronary Drug Project Research Group. Circulation. 1980; 62: V59-62.

47. Critical Leg Ischaemia Prevention Study G, Catalano M, Born G, Peto R. Prevention of serious vascular events by aspirin amongst patients with peripheral arterial disease: randomized, double-blind trial. J Intern Med. 2007; 261: $276-84$

48. Effect of aspirin alone and aspirin plus dipyridamole in early diabetic retinopathy. A multicenter randomized controlled clinical trial. The DAMAD Study Group. Diabetes. 1989; 38: 491-8.

49. Secondary prevention in non-rheumatic atrial fibrillation after transient ischaemic attack or minor stroke. EAFT (European Atrial Fibrillation Trial) Study Group. Lancet. 1993; 342: 1255-62.

50. Diener HC, Cunha L, Forbes C, Sivenius J, Smets P, Lowenthal A. European Stroke Prevention Study. 2. Dipyridamole and acetylsalicylic acid in the secondary prevention of stroke. J Neurol Sci. 1996; 143: 1-13.
51. Aspirin effects on mortality and morbidity in patients with diabetes mellitus. Early Treatment Diabetic Retinopathy Study report 14. ETDRS Investigators. JAMA. 1992; 268: 1292-300.

52. Hansson L, Zanchetti A, Carruthers SG, Dahlof B, Elmfeldt D, Julius S, et al. Effects of intensive blood-pressure lowering and low-dose aspirin in patients with hypertension: principal results of the Hypertension Optimal Treatment (HOT) randomised trial. HOT Study Group. Lancet. 1998; 351: 1755-62.

53. Ogawa H, Nakayama M, Morimoto T, Uemura S, Kanauchi M, Doi N, et al. Low-dose aspirin for primary prevention of atherosclerotic events in patients with type 2 diabetes: a randomized controlled trial. JAMA. 2008; 300: 2134-41.

54. Saito Y, Okada S, Ogawa H, Soejima H, Sakuma M, Nakayama M, et al. Low-Dose Aspirin for Primary Prevention of Cardiovascular Events in Patients With Type 2 Diabetes Mellitus: 10-Year Follow-Up of a Randomized Controlled Trial. Circulation. 2017; 135: 659-70.

55. Okada S, Morimoto T, Ogawa H, Sakuma M, Matsumoto C, Soejima H, et al. Effect of Aspirin on Cancer Chemoprevention in Japanese Patients With Type 2 Diabetes: 10-Year Observational Follow-up of a Randomized Controlled Trial. Diabetes Care. 2018; 41: 1757-64.

56. Yokoyama K, Ishizuka N, Uemura N, Mizokami Y, Hiraishi H, Murata M, et al. Effects of daily aspirin on cancer incidence and mortality in the elderly Japanese. Res Pract Thromb Haemost. 2018; 2: 274-81.

57. Persantine and aspirin in coronary heart disease. The Persantine-Aspirin Reinfarction Study Research Group. Circulation. 1980; 62: 449-61.

58. Steering Committee of the Physicians' Health Study Research G. Final report on the aspirin component of the ongoing Physicians' Health Study. N Engl J Med. 1989; 321: 129-35.

59. Sturmer T, Glynn RJ, Lee IM, Manson JE, Buring JE, Hennekens CH. Aspirin use and colorectal cancer: post-trial follow-up data from the Physicians' Health Study. Ann Intern Med. 1998; 128: 713-20.

60. Belch J, MacCuish A, Campbell I, Cobbe S, Taylor R, Prescott R, et al. The prevention of progression of arterial disease and diabetes (POPADAD) trial: factorial randomised placebo controlled trial of aspirin and antioxidants in patients with diabetes and asymptomatic peripheral arterial disease. BMJ. 2008; 337: a1840

61. de Gaetano G, Collaborative Group of the Primary Prevention P. Low-dose aspirin and vitamin $\mathrm{E}$ in people at cardiovascular risk: a randomised trial in general practice. Collaborative Group of the Primary Prevention Project. Lancet. 2001; 357: 89-95.

62. Vidal AC, Howard LE, Moreira DM, Castro-Santamaria R, Andriole GL, Freedland SJ. Aspirin, NSAIDs, and risk of prostate cancer: results from the REDUCE study. Clin Cancer Res. 2015; 21: 756-62.

63. Swedish Aspirin Low-Dose Trial (SALT) of $75 \mathrm{mg}$ aspirin as secondary prophylaxis after cerebrovascular ischaemic events. The SALT Collaborative Group. Lancet. 1991; 338: 1345-9.

64. Juul-Moller S, Edvardsson N, Jahnmatz B, Rosen A, Sorensen S, Omblus R. Double-blind trial of aspirin in primary prevention of myocardial infarction in patients with stable chronic angina pectoris. The Swedish Angina Pectoris Aspirin Trial (SAPAT) Group. Lancet. 1992; 340: 1421-5.

65. Hull MA, Sprange K, Hepburn T, Tan W, Shafayat A, Rees CJ, et al. Eicosapentaenoic acid and aspirin, alone and in combination, for the prevention of colorectal adenomas (seAFOod Polyp Prevention trial): a multicentre, randomised, double-blind, placebo-controlled, $2 \times 2$ factorial trial. Lancet. 2018; 392: 2583-94.

66. Thrombosis prevention trial: randomised trial of low-intensity oral anticoagulation with warfarin and low-dose aspirin in the primary prevention of ischaemic heart disease in men at increased risk. The Medical Research Council's General Practice Research Framework. Lancet. 1998; 351: 233-41.

67. Logan RF, Grainge MJ, Shepherd VC, Armitage NC, Muir KR, uk CAPTG. Aspirin and folic acid for the prevention of recurrent colorectal adenomas. Gastroenterology. 2008; 134: 29-38.

68. Farrell B, Godwin J, Richards S, Warlow C. The United Kingdom transient ischaemic attack (UK-TIA) aspirin trial: final results. J Neurol Neurosurg Psychiatry. 1991; 54: 1044-54

69. Cook NR, Lee IM, Gaziano JM, Gordon D, Ridker PM, Manson JE, et al. Low-dose aspirin in the primary prevention of cancer: the Women's Health Study: a randomized controlled trial. JAMA. 2005; 294: 47-55.

70. Rothwell PM, Wilson M, Price JF, Belch JF, Meade TW, Mehta Z. Effect of daily aspirin on risk of cancer metastasis: a study of incident cancers during randomised controlled trials. Lancet. 2012; 379: 1591-601.

71. Haykal T, Barbarawi M, Zayed Y, Yelangi A, Dhillon H, Goranta S, et al. Safety and efficacy of aspirin for primary prevention of cancer: a meta-analysis of randomized controlled trials. J Cancer Res Clin Oncol. 2019; 145: 1795-809.

72. $\mathrm{Wu} \mathrm{Q}$, Leung EL. The evidence strength of a meta-analysis of aspirin for primary prevention of cancer. J Cancer Res Clin Oncol. 2019

73. Sutcliffe P, Connock M, Gurung T, Freeman K, Johnson S, Kandala NB, et al. Aspirin for prophylactic use in the primary prevention of cardiovascular disease and cancer: a systematic review and overview of reviews. Health Technol Assess. 2013; 17: 1-253.

74. Torjesen I. Daily aspirin reduces risk of developing and dying from cancer, researchers find. BMJ. 2014; 349: g5037.

75. Burn J, Gerdes AM, Macrae F, Mecklin JP, Moeslein G, Olschwang S, et al. Long-term effect of aspirin on cancer risk in carriers of hereditary colorectal cancer: an analysis from the CAPP2 randomised controlled trial. Lancet. 2011; 378: 2081-7. 
76. Rothwell PM, Wilson M, Elwin CE, Norrving B, Algra A, Warlow CP, et al. Long-term effect of aspirin on colorectal cancer incidence and mortality: 20-year follow-up of five randomised trials. Lancet. 2010; 376: 1741-50.

77. Drew DA, Chin SM, Gilpin KK, Parziale M, Pond E, Schuck MM, et al. ASPirin Intervention for the REDuction of colorectal cancer risk (ASPIRED): a study protocol for a randomized controlled trial. Trials. 2017; 18: 50.

78. Hull MA, Sprange K, Hepburn T, Tan W, Shafayat A, Rees CJ, et al. Eicosapentaenoic acid and/or aspirin for preventing colorectal adenomas during colonoscopic surveillance in the NHS Bowel Cancer Screening Programme: the seAFOod RCT. Southampton (UK). 2019.

79. Skriver C, Dehlendorff C, Borre M, Brasso K, Larsen SB, Dalton SO, et al. Use of Low-Dose Aspirin and Mortality After Prostate Cancer Diagnosis: A Nationwide Cohort Study. Ann Intern Med. 2019; 170: 443-52.

80. Zhang R, Pan T, Xiang Y, Zhang M, Feng J, Liu S, et al. beta-Elemene Reverses the Resistance of p53-Deficient Colorectal Cancer Cells to 5-Fluorouracil by Inducing Pro-death Autophagy and Cyclin D3-Dependent Cycle Arrest. Front Bioeng Biotechnol. 2020; 8: 378.

81. Chen L, Liu Y, Zhang Q, Zhang M, Han X, Li Q, et al. p53/PCDH17/Beclin-1 Proteins as Prognostic Predictors for Urinary Bladder Cancer. J Cancer. 2019; 10: 6207-16.

82. Chen B, Zhang RN, Fan XX, Wang J, Xu C, An B, Wang Q, Wang J, Leung ELH, Sui $\mathrm{XB}, \mathrm{Wu} \mathrm{QB}$. Clinical diagnostic value of long non-coding RNAs in Colorectal Cancer: A systematic review and meta-analysis. J Cancer 2020; 11(18): 5518-5526 2020 